\title{
Review of the anatase to rutile phase transformation
}

\author{
Dorian A. H. Hanaor • Charles C. Sorrell
}

Received: 21 May 2010/ Accepted: 23 November 2010/Published online: 8 December 2010

(C) Springer Science+Business Media, LLC 2010

\begin{abstract}
Titanium dioxide, $\mathrm{TiO}_{2}$, is an important photocatalytic material that exists as two main polymorphs, anatase and rutile. The presence of either or both of these phases impacts on the photocatalytic performance of the material. The present work reviews the anatase to rutile phase transformation. The synthesis and properties of anatase and rutile are examined, followed by a discussion of the thermodynamics of the phase transformation and the factors affecting its observation. A comprehensive analysis of the reported effects of dopants on the anatase to rutile phase transformation and the mechanisms by which these effects are brought about is presented in this review, yielding a plot of the cationic radius versus the valence characterised by a distinct boundary between inhibitors and promoters of the phase transformation. Further, the likely effects of dopant elements, including those for which experimental data are unavailable, on the phase transformation are deduced and presented on the basis of this analysis.
\end{abstract}

\section{Background}

Titanium dioxide, also known as titania, is of growing interest due to its proven ability to function as a photocatalyst and facilitate important environmentally beneficial reactions, such as water splitting to generate hydrogen and treatment of polluted air and water.

D. A. H. Hanaor $(\bowtie) \cdot$ C. C. Sorrell

School of Materials Science and Engineering, University of New

South Wales, Sydney, NSW 2052, Australia

e-mail: dorian@student.unsw.edu.au

C. C. Sorrell

e-mail: c.sorrell@unsw.edu.au
Titanium dioxide occurs as two important polymorphs, the stable rutile and metastable anatase. These polymorphs exhibit different properties and consequently different photocatalytic performances. Anatase transforms irreversibly to rutile at elevated temperatures. This transformation does not have a unique temperature and the processes that are involved in the transformation as well as the methods to inhibit or promote this transformation have not been reviewed comprehensively to date.

The present work aims to clarify the differences between the two main polymorphs of titanium dioxide, the nature of the anatase to rutile transformation, and the principles of controlling phase composition through the inhibition or promotion of the transformation of anatase to rutile.

\section{Titania polymorphs}

Titanium dioxide, the only naturally occurring oxide of titanium at atmospheric pressure, exhibits three polymorphs: rutile, anatase, and brookite [1-7]. While rutile is the stable phase, both anatase and brookite are metastable; the latter is difficult to synthesise and so is seldom studied [8]. Another five high-pressure phases of $\mathrm{TiO}_{2}$ have been reported:

- $\mathrm{TiO}_{2} \mathrm{II}$ or srilankite, an orthorhombic polymorph of the lead oxide structure

- Cubic fluorite-type polymorph

- Pyrite-type polymorph

- Monoclinic baddeleyite-type polymorph

- Cotunnite-type polymorph

The stability of these phases has been discussed in several publications [4, 7, 9-12]. However, these are of minor significance for research and development applications. 
Titania properties

Table 1 outlines the basic properties of rutile and anatase.

Titania applications

The primary application of titanium dioxide is as a white pigment in paints, food colouring, cosmetics, toothpastes, polymers, and other instances in which white colouration is desired [13]. The reason for this is the high refractive indices of rutile and anatase, which result in high reflectivity from the surfaces. Consequently, titanias of small particle size and correspondingly high surface areas are used owing to the resultant opacifying power and brightness. However, paints utilise polymeric binders to fix the pigment and, when in contact with titania, the polymer may oxidise when exposed to sunlight. This effect is known as chalking and, in addition to the direct degrading effect of ultraviolet (UV) radiation, is accelerated by the photocatalytic activity of $\mathrm{TiO}_{2}$, which also is enhanced by the high surface area of this material [25].

The potential for the application of the photocatalytic effect in $\mathrm{TiO}_{2}$ has attracted considerable interest over the last three decades. Titania photocatalysts are known to be applicable in a range of important technological areas:

Table 1 Properties of anatase and rutile

\begin{tabular}{llll}
\hline Property & Anatase & Rutile & Reference \\
\hline Crystal structure & Tetragonal & Tetragonal & {$[13]$} \\
Atoms per unit cell (Z) & 4 & 2 & {$[14,15]$} \\
Space group & $l_{a}^{4} \mathrm{md}$ & $P \frac{4_{2}}{m} \mathrm{~nm}$ & {$[14,16]$} \\
Lattice parameters $(\mathrm{nm})$ & $a=0.3785$ & $a=0.4594$ & {$[14,15]$} \\
& $c=0.9514$ & $c=0.29589$ & \\
Unit cell volume $\left(\mathrm{nm}^{3}\right)^{\mathrm{a}}$ & 0.1363 & 0.0624 & \\
Density (kg m $\left.{ }^{-3}\right)$ & 3894 & 4250 & {$[14,15]$} \\
Calculated indirect band gap & & {$[8,17-20]$} \\
$(\mathrm{eV})$ & $3.23-3.59$ & $3.02-3.24$ & \\
$(\mathrm{~nm})$ & $345.4-383.9$ & $382.7-410.1$ & \\
Experimental band gap & & & {$[8,19,21]$} \\
$(\mathrm{eV})$ & $\sim 3.2$ & $\sim 3.0$ & \\
$\quad(\mathrm{~nm})$ & $\sim 387$ & $\sim 413$ & \\
Refractive index & $2.54,2.49$ & $2.79,2.903$ & {$[13,22]$} \\
Solubility in $\mathrm{HF}$ & Soluble & Insoluble & {$[23]$} \\
Solubility in $\mathrm{H}_{2} \mathrm{O}$ & Insoluble & Insoluble & {$[13]$} \\
Hardness $(\mathrm{Mohs})$ & $5.5-6$ & $6-6.5$ & {$[24]$} \\
Bulk modulus $(\mathrm{GPa})$ & 183 & 206 & {$[20]$} \\
\hline
\end{tabular}

${ }^{a}$ Since the numbers of atoms per unit cell is halved upon going from rutile to anatase, the lattice parameters and unit cell volumes must be viewed accordingly
- Energy

Electrolysis of water to generate hydrogen [26-30]. Dye-sensitised solar cells (DSSCs) [31-33].

- Environment

Air purification [34, 35].

Water treatment [36-40].

- Built Environment

Self-cleaning coatings [34, 38, 39, 41-50].

Non-spotting glass [47, 51].

- Biomedicine

Self-sterilising coatings [52, 53].

Photocatalytic effect

Photocatalysed reactions for applications such as those mentioned above are facilitated through the presence of adsorbed radicals (from air or water) on the $\mathrm{TiO}_{2}$ surface [28, 44-47, 49, 54-56]. These radicals, which are atomic species with a free unpaired electron, are formed upon reaction of an adsorbed molecule (such as $\mathrm{O}_{2}$ or $\mathrm{H}_{2} \mathrm{O}$ ) with a photo-generated charge carrier (from an electron-hole pair or exciton) when $\mathrm{TiO}_{2}$ is exposed to radiation exceeding its band gap; this radiation normally is in the UV wavelength region (290-380 nm). These electron-hole pairs are formed when an electron is elevated from the valence to the conducting band, leaving behind an electron hole, as shown in Fig. 1.

The electrons in the conduction band facilitate reduction of electron acceptors and the holes facilitate oxidation of electron donors [57]. Examples of the photo-generation of radicals in atmospheric and aqueous environments are given in the following reactions [28, 57-59]:

$\mathrm{TiO}_{2}+h v \leftrightarrow \mathrm{h}^{+}+\mathrm{e}^{-}$

$\mathrm{h}^{+}+\mathrm{H}_{2} \mathrm{O}_{\text {absorbed }} \leftrightarrow \mathrm{H}^{+}+{ }^{\bullet} \mathrm{OH}$

$\mathrm{h}^{+}+\mathrm{OH}_{\text {absorbed }}^{-} \leftrightarrow{ }^{\bullet} \mathrm{OH}$

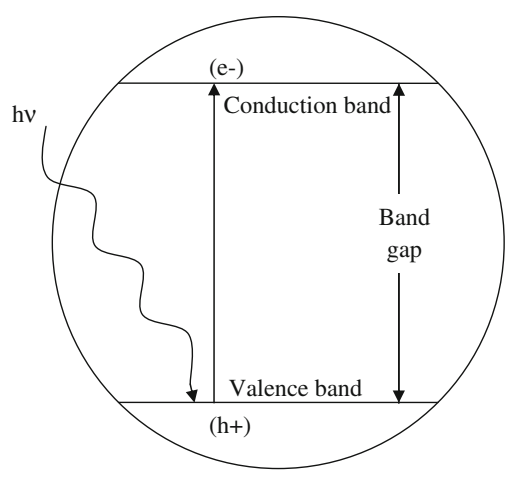

Fig. 1 Schematic illustration of photo-generation of charge carriers in a photocatalyst 
$\mathrm{e}^{-}+\mathrm{O}_{2 \text { absorbed }} \leftrightarrow{ }^{\bullet} \mathrm{O}_{2}^{-}$

In this notation, an unpaired electron is represented by a point, a valence band electron hole is represented by $\mathrm{h}^{+}$, and a conduction band electron is represented by $\mathrm{e}^{-}$.

These mechanisms have been described elsewhere in greater detail for the decomposition of organic pollutants, as shown in Fig. 2 [38, 46, 56, 57, 60] and the splitting of water [26, 27, 29].

The generation of positive and negative charge carriers by UV radiation and their tendency to recombine are competing phenomena, the rates of which govern whether or not a semiconductor can function as a photocatalyst [61]. A key factor in titania's photocatalytic ability is its high surface area, the same property that contributes to its optical properties. A high surface area leads to a higher density of localised states, which involve electrons with energies between the conduction band and valence band [62]. These electrons are present owing to terminated and unsaturated bonds on the surfaces, and these localised states provide beneficial charge separation in the form of trapping sites for photo-generated charge carriers [63]. Titania has a relatively slow rate of charge carrier recombination in comparison with other semiconductors [64], which is an advantage since it has been suggested that a photo-generated electron-hole pair needs a lifetime of at least $0.1 \mathrm{~ns}$ for chemical reactions to be facilitated $[64,65]$.

In the presence of reactive species adsorbed on the catalyst surface, photogenerated charge carriers may transfer to these adsorbates to form radicals rather than recombine [28]. Thus, an effective photocatalyst also is likely to have a high density of reactive adsorbed species for good performance to be achieved.

Despite the larger experimental band gap of anatase of $\sim 3.2 \mathrm{eV}$, compared with $\sim 3.0 \mathrm{eV}$ for rutile $[8,66-68]$, the photocatalytic performance of anatase generally is considered superior to that of the more stable rutile. This is attributed to a higher density of localised states and consequent surface-adsorbed hydroxyl radicals and slower charge carrier recombination in anatase relative to rutile $[58,60$, 69-72], parameters that contribute to improved performance. The higher rate of electron-hole recombination in rutile is considered to result from this material's typically

hv
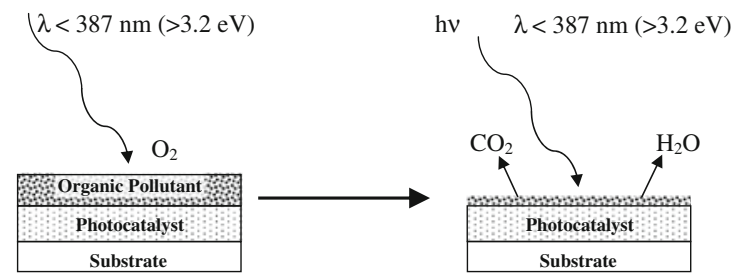

Fig. 2 Schematic illustration of the photo-oxidation of an organic pollutant on a photocatalyst surface larger grain size $[55,73]$ and its resultant lower capacity to adsorb species [60, 74, 75].

It may be noted that, owing to the different crystal structures and associated exposed planes of the two polymorphs, anatase has been reported to have a lower surface enthalpy and lower surface free energy than rutile [76]. Hence, it would be expected that the wetting of anatase by water would be less than that of rutile since higher surface free energies generally contribute to hydrophilicity [77]. Since a high density of adsorbed species would be expected from a hydrophilic material, rutile could be anticipated to exhibit superior photocatalytic performance. It may be noted that there are no reports of rutile's exhibiting higher levels of adsorbed species.

The photoactivity of anatase and rutile have been examined and interpreted by Sclafani and Herrmann [58] with reference to the densities of surface-adsorbed species. This study showed that higher levels of radicals adsorbed on the anatase surface gives rise to significantly higher photoactivity than rutile. This result was reported to be due to a higher surface area as well as a higher photoactivity per unit of surface area. A similar result was found by Augustynski [71], who reported that surface-bonded peroxo species on anatase were absent from rutile surfaces.

In contrast to the widely reported photocatalytic superiority of anatase, several publications have suggested that, in some cases, rutile may be advantageous for certain applications [23, 25, 78-80]. These studies involved highsurface-area rutile of acicular morphology [25], rutile containing residual anatase [78], and iron-doped rutile [81]. It is possible that electron transfer between rutile and a residual quantity of anatase [78] may facilitate improved photo-oxidative reactions, as in mixed-phase titania catalysts. Therefore, in light of importance of surface area, morphology, and doping, an understanding of the titania polymorphs, their transformation, and the methods by which they can be controlled are likely to be critical to achieving phase-optimised photocatalytic performance.

\section{Formation and analysis of titania phases}

Phase formation during synthesis of $\mathrm{TiO}_{2}$

In the synthesis of $\mathrm{TiO}_{2}$ films by various methods, the initial crystalline $\mathrm{TiO}_{2}$ phase formed is generally anatase $[82,83]$. From a structural perspective, this could be due to the greater ease of the short-range ordered $\mathrm{TiO}_{6}$ octahedra in arranging into long-range ordered anatase structure owing to the less-constrained molecular construction of anatase relative to rutile [84]. Alternatively, from a thermodynamic perspective, the more rapid recrystallisation of anatase could be due to the lower surface free energy of this polymorph, despite the lower Gibbs free energy of 
rutile [6, 76]. That is, the higher surface free energy of rutile crystallites may favour the crystallisation of anatase.

It should be noted that it is possible to form rutile under near room temperature conditions [54, 83, 103, 104]. Hydrothermal methods of synthesis, which can facilitate the precipitation of crystalline $\mathrm{TiO}_{2}$ directly from a liquid phase, can be controlled to precipitate rutile. Aside from this method, rutile is obtained only through high-temperature treatment. Table 2 summarizes the phases that can result from various synthesis methods at room temperature and at elevated temperatures.

Anatase to rutile transformation

Control of the conditions that affect the kinetics to control the anatase to rutile phase transformation is of considerable interest. This is particularly the case for high-temperature processes and applications, such as gas sensors and porous gas separation membranes [105-107], where the phase transformation may occur, thereby altering the properties and performance of these devices. Therefore, an understanding of the stabilities of the $\mathrm{TiO}_{2}$ polymorphs, the kinetics of their phase transformation, and the processes involved in controlling them is essential to the ability to obtain single-phase or multiphase microstructures. These issues are critical to the long-term consistency of devices, where retention of anatase or a multiphase microstructure may not be possible, thereby potentially requiring processing designed to produce singlephase rutile. Similarly, limitations in temperature while desiring a specific polymorph, such as rutile, may require manipulation of the materials and processing conditions so as to enhance the direction formation of rutile.

The generation of the phases of $\mathrm{TiO}_{2}$ depends significantly on the synthesis parameters, which in turn affect the product. The kinetics of these processes typically are considered in terms of temperature and time. In terms of the former, pure bulk anatase is considered widely to begin to transform irreversibly to rutile in air at $\sim 600{ }^{\circ} \mathrm{C}[6,66$, 99]; however, the reported transition temperatures vary in the range $400-1200{ }^{\circ} \mathrm{C}[42,66,108-112]$ owing to the use of different methods of determining the transition temperatures, raw materials, and processing methods. The anatase to rutile transformation is not instantaneous; it is timedependent because it is reconstructive [2, 109, 113]. Consequently, the kinetics of the phase transformation must be interpreted in terms of all of the factors that influence the requisite temperature-time conditions. These parameters for undoped anatase are:

- Particle size

- Particle shape (aspect ratio)

- Surface area

- Atmosphere

- Volume of sample

- Nature of sample container

- Heating rate

- Soaking time

- Impurities (from raw materials and container)

- Measurement technique

The anatase to rutile transition, sometimes referred to as the ART, is a nucleation and growth process [106, 109]. As mentioned, the kinetics of this transition are dependent on variables such as impurities, morphology, sample preparation method, heat flow conditions, etc. In the absence of impurities, dopants, secondary phases, or other types of contamination, rutile forms as fine laths with the product phase's (100) planes parallel to the (112) planes of the parent anatase [106, 111, 114]. In pure anatase, rutile may nucleate at (112) twin interfaces in anatase [106, 114] as these sites are structurally similar to rutile.

Both anatase, space group I4/amd, and rutile, space group $\mathrm{P}_{2} / \mathrm{mnm}$, are tetragonal in structure. Both crystal

Table 2 Common synthesis methods of titanium dioxide and resultant phases

\begin{tabular}{|c|c|c|c|c|c|c|}
\hline \multirow[t]{2}{*}{ Synthesis method } & \multirow[t]{2}{*}{ Mechanism } & \multicolumn{4}{|c|}{ Phases formed } & \multirow[t]{2}{*}{ References } \\
\hline & & Amorphous & Anatase & Rutile & Anatase + rutile & \\
\hline $\begin{array}{l}\text { Room temperature } \\
\text { hydrolysis of } \mathrm{TiCl}_{4}\end{array}$ & $\begin{array}{l}\text { Precipitation from room temperature solutions of } \\
\mathrm{TiCl}_{4}\end{array}$ & $\checkmark$ & & & & {$[85,86]$} \\
\hline $\begin{array}{l}\text { Room temperature sol- } \\
\text { gel synthesis }\end{array}$ & Hydrolysis of $\mathrm{TiCl}_{4}$ or an organo-metallic compound & $\boldsymbol{\sim}$ & & & & {$[87-90]$} \\
\hline Flame pyrolysis of $\mathrm{TiCl}_{4}$ & $\begin{array}{l}\text { Combustion of } \mathrm{TiCl}_{4} \text { with oxygen; used in industrial } \\
\text { processes }\end{array}$ & & $\checkmark$ & & $\checkmark$ & [91-93] \\
\hline $\begin{array}{l}\text { Solvothermal/ } \\
\text { hydrothermal }\end{array}$ & $\begin{array}{l}\text { Precipitation of } \mathrm{TiO}_{2} \text { from aqueous or organic solution } \\
\text { at elevated temperatures }\end{array}$ & & $\checkmark$ & $\boldsymbol{V}$ & $\boldsymbol{\alpha}$ & $\begin{array}{l}{[66,84,} \\
94-99]\end{array}$ \\
\hline $\begin{array}{l}\text { Chemical vapour } \\
\text { deposition }\end{array}$ & Spraying of Ti-bearing solution & $\boldsymbol{\sim}$ & $\checkmark$ & $\boldsymbol{V}$ & $\boldsymbol{\sim}$ & {$[100,101]$} \\
\hline $\begin{array}{l}\text { Physical vapour } \\
\text { deposition }\end{array}$ & $\begin{array}{l}\text { Deposition of evaporated } \mathrm{Ti} \text { and its subsequent } \\
\text { oxidation }\end{array}$ & $\checkmark$ & $\checkmark$ & $\boldsymbol{V}$ & $\checkmark$ & {$[21,102]$} \\
\hline
\end{tabular}



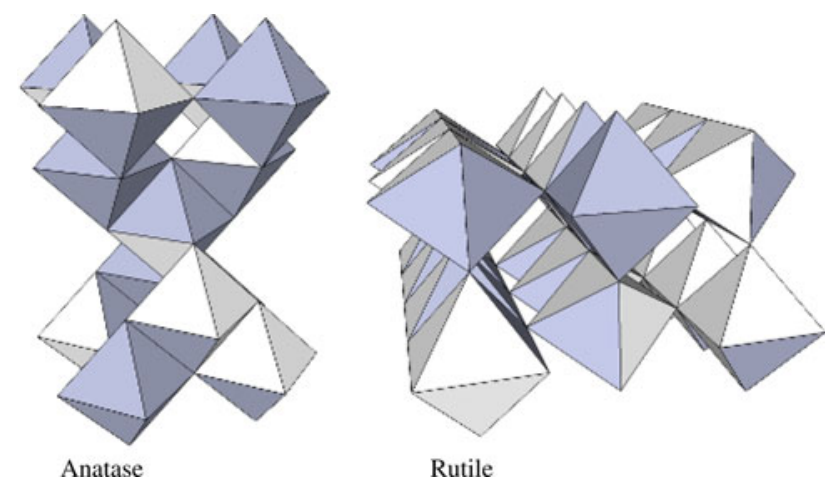

Fig. 3 Three-dimensional representation of the arrangement of $\mathrm{TiO}_{6}$ octahedra in anatase and rutile showing 4 edge sharing connectivity in anatase and 2 edge sharing connectivity in rutile

structures consist of $\mathrm{TiO}_{6}$ octahedra, sharing four edges in anatase and two in rutile $[8,9,69,115,116]$. These structures are illustrated in Figs. 3 and 4.

The anatase to rutile transformation is reconstructive, which means that the transformation involves the breaking and reforming of bonds [117]. This is in contrast to a displacive transformation, in which the original bonds are distorted but retained. The reconstructive anatase to rutile transformation involves a contraction of the $c$-axis and an overall volume contraction of $\sim 8 \%[109,118,119]$. This

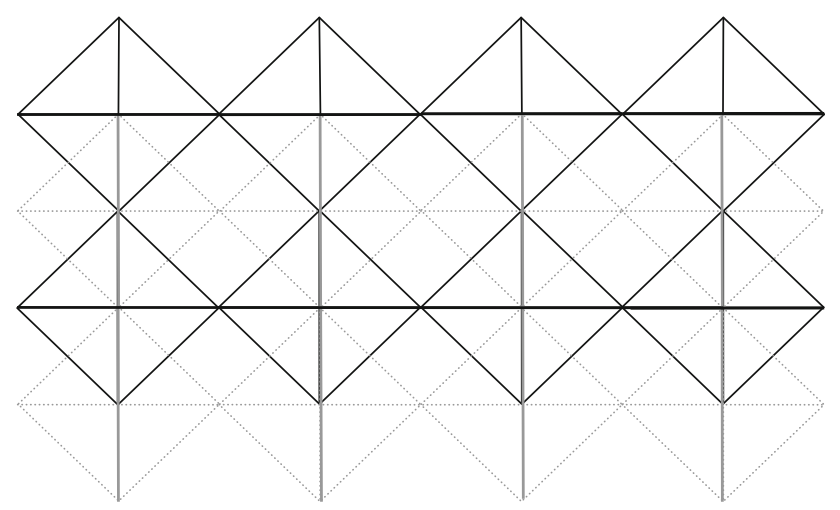

Anatase

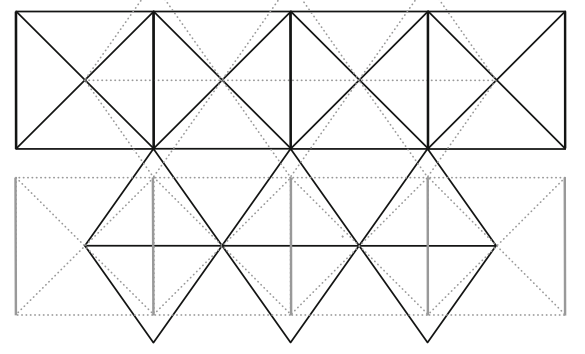

Rutile

Fig. 4 Two-dimensional projection, down the $c$-axis, of the $\mathrm{TiO}_{6}$ octahedra in anatase and rutile; shared edges in bold lines volume contraction explains the higher density of rutile relative to anatase. In the course of the transition to rutile, the (112) planes in anatase are retained as the (100) planes in the rutile product $[67,115]$. The $c$-axis of anatase appears to be significantly longer than that of rutile only because anatase has more atoms per unit cell than rutile.

Phase differentiation and quantification of anatase/rutile ratio

\section{$X$-ray diffraction}

Examination of the kinetics of the anatase to rutile phase transformation may involve assessment of the relative quantities of anatase and rutile following heating in specific conditions of heating rate, temperature, and time in order to examine the effects of parameters such as dopants, particle size, and atmosphere on the resultant phase assemblage.

Quantification of phase proportions usually is carried out by X-ray diffraction (XRD) [1, 78, 81, 105, 120-125]. Such analyses often are done using the method of Spurr and Myers [126], which utilises the ratio of the rutile (110) peak at $27.355^{\circ} 2 \theta$ to the anatase (101) peak at $25.176^{\circ} 2 \theta$. The ratio of the intensities of these peaks, $I_{\mathrm{R}} / I_{\mathrm{A}}$, is used in the empirically determined formula in Eq. 5 to give the weight fractions of anatase and rutile:

$\frac{W_{\mathrm{R}}}{W_{\mathrm{A}}}=1.22 \frac{I_{\mathrm{R}}}{I_{\mathrm{A}}}-0.028 \infty$

Despite the number of the above researchers who have utilised this formula in their investigations into the ART, consideration of the relevant issues reveals a number of factors that may affect the accuracy of the results:

- Preferred orientation: rutile and/or anatase crystallites may be present in preferred orientation owing to morphological and/or sample preparation effects, which may lead to altered XRD relative peak intensities.

- Encapsulation: rutile crystallites may grow as an overlayer of rutile on anatase particles [80] or, alternatively, rutile may form in the bulk of the anatase grains, leaving a surface layer of anatase on rutile particles [112], thereby compromising the basis for the intensities of the XRD peaks.

- Lattice distortion: the presence of dissolved dopants and/or impurities, especially if differential solubility occurs, may alter the peak heights and areas, thereby altering the relative intensities of the XRD peaks.

- Degree of crystallinity: the presence of dopants may increase (nucleation) or decrease (lattice distortion/ stress) the degree of crystallinity, which would alter the consequent peak intensities, particularly if these dopants are preferentially present in one of the phases. 
- Grain size: the transition to rutile is accompanied by significant grain growth [127, 128], resulting in large rutile grains and small anatase grains, which would alter the ratios of XRD peak intensities.

- Morphology: rutile may form in an acicular morphology, which would alter the XRD peak intensities of these grains relative to typically equiaxed rutile [129].

- Surface nucleation of rutile: enhanced surface nucleation of rutile owing to heat (thermal gradients) and segregation (chemical gradients) effects would increase the XRD peak intensities of this phase; this would be similar to encapsulation.

Thus, it is important to consider that the validity of the data resulting from Eq. 5 depends on adequate assessment of the preceding parameters and the application of materials and processes designed to achieve samples of representative chemistry, mineralogy, and microstructure. If these cannot be attained, alternative materials, fabrication methods, and analytical techniques may be required.

\section{Laser Raman microspectroscopy}

Laser Raman microspectroscopy also has been employed effectively to differentiate the anatase and rutile [25, 80, 124, 130-133]. The titania polymorphs exhibit distinct Raman spectra that can be used for qualitative and quantitative mineralogical analysis. Laser Raman microspectroscopy has been applied quantitatively for on-line process control in the manufacture of titania powder by Hunstsman Tioxide, Inc. [134].

Laser Raman microspectroscopy has several advantages:

- Minimal or no sample preparation

- Nondestructive

- Local and general phase analyses $(\leq 1 \mu \mathrm{m}$ beam diameter)

- Mapping capability

- Rapid analyses ( 1 min scan)

- No preferred orientation effect

- Greater sensitivity than XRD

- Sensitive to nanoscale phases
Figure 5 contrasts experimental scans of identical samples of rutile and anatase $\mathrm{TiO}_{2}$ by XRD and laser Raman microspectroscopy carried out by the authors and confirmed by comparison with reference patterns and spectra [135-137].

The main strength with laser Raman microspectroscopy is its applicability to nanoscale thin films. When glancingangle XRD is used, the instrument requires considerable calibration, the peaks are very diffuse, and the background is such that any amorphous phase, if present, cannot be ascertained. With laser Raman microspectroscopy, none of these problems are experienced, so the analyses are more efficient and more sensitive.

\section{Differential solubility}

A more direct method of measuring the rutile/anatase proportions was employed by Ohno et al. [23, 78, 138]. This method involved using hydrofluoric acid (HF) to dissolve the anatase phase, leaving the rutile phase intact. This method has the disadvantages of health risk, potential loss of material during washing, loss of anatase, and potential for slight solubility of rutile. However, this method could be useful for the removal of trace levels of anatase in order to enhance the purity of rutile powders.

\section{Impedance spectroscopy}

Another method of measurement was employed by Suresh et al. [139], who applied impedance spectroscopy to examine the anatase to rutile transformation. Since this method relies on the difference in resistivity between the two phases, it suffers two innate uncertainties associated with electrical resistivity measurement. First, the resistivity is a function of the grain connectivity, which is a microstructural factor rather than a mineralogical one. Second, dopants and impurities have a profound influence on the electrical properties, so their presence inevitably would affect the resistivities in a differential manner. Despite these reservations, this method has been used in conjunction with
Fig. 5 XRD patterns and laser Raman spectra of rutile and anatase powders [129]
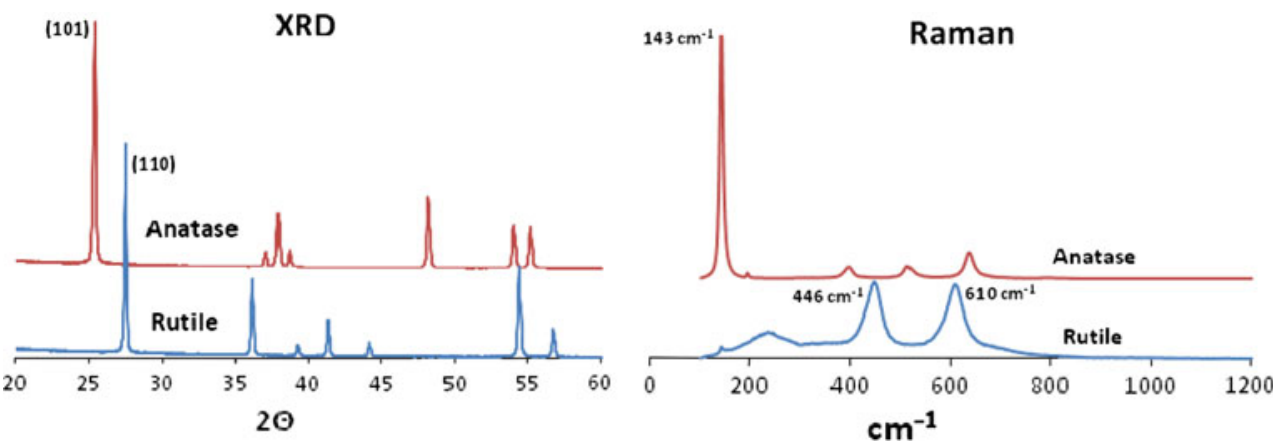
XRD and differential thermal analysis (DTA) to ascertain the effect of doping with silica [140].

In general, the XRD method of phase analysis is the most generally used for bulk qualitative and quantitative analyses (using Eq. 5). Experimental calibration has demonstrated that, despite a number of potential flaws in the quantitative method of XRD phase analysis of titania, this method gives reasonably accurate and consistent results [129].

Rutile-anatase mixtures

Mixed-phase photocatalysts with rutile-anatase compositions have been reported to exhibit enhanced photoactivity relative to single-phase titania $[23,34,54,55,68,73,80$, $110,112,125,130,131,141-146]$. It is considered widely that this is a result of improved charge carrier separation, possibly through the trapping of electrons in rutile and the consequent reduction in electron-hole recombination [78, 117, 147]. Surface trapping of holes together with lattice trapping of electrons also has been reported [78, 125]. In consequence, Degussa P-25 is marketed as a mixed-phase titania photocatalyst and it is utilised as a reference material in many studies. It should be noted that the high performance observed for Degussa P-25 is reported to stem primarily from this material's high specific surface area [58]. This nanocrystalline material, formed by flame pyrolysis, consists of $80 \mathrm{wt} \%$ anatase and $20 \mathrm{wt} \%$ rutile. However, Bacsa and Kiwi [54] reported that a photocatalyst containing $70 \mathrm{wt} \%$ anatase and $30 \mathrm{wt} \%$ rutile, with a surface area of $72.0 \mathrm{~m}^{2} / \mathrm{g}$ exhibited greater photocatalytic performance than the Degussa P-25 reference, which has a specific surface area of $49.2 \mathrm{~m}^{2} / \mathrm{g}$.

Since the particle size and surface area depend strongly on the preparation method, it would be misleading to interpret the photocatalytic performance solely in terms of the phase composition. As an example of the importance of the effect of the processing conditions on these parameters, variations in grain size, crystallite size, surface area, morphology, and phase distribution obtained during sol-gel synthesis have been observed to be highly dependent on the precursor solutes and solvents used [36, 46, 54], calcining temperatures $[55,110,148,149]$, and $\mathrm{pH}[54,73,83,114$, $139,150]$.

Within a certain set of processing protocols, it is possible to obtain mixed-phase photocatalysts of nominally pure titania through variation of the kinetics (heating rate, soak time, and soak temperature). In such cases, a comprehensive understanding of the following effects must be in place:

- Time

- Temperature
- Atmosphere

- Intrinsic chemical composition (purity of raw materials)

- Extrinsic contamination (from processing)

- Chemical homogeneity (e.g., segregation)

- Microstructural homogeneity (e.g., grain boundary precipitates)

- Thermal homogeneity during heating (e.g., resulting from sample size and shape)

- Mineralogical phase assemblage

- Particle size distribution

- Agglomerate size distribution

- Grain morphology

- Agglomerate morphology

In contrast to the processing of nominally pure samples, mixed-phase titania of controlled rutile/anatase ratios also can be obtained by doping. However, doping inevitably affects the semiconducting properties of materials, which may be disadvantageous to the photocatalytic performance. Alternatively, as discussed subsequently, doping also may act advantageously through reduction in the band gap and improvement in the charge carrier separation and associated extended exciton lifetime [18, 68, 73, 151].

\section{Thermodynamics and kinetics of the anatase to rutile phase transformation}

Stability of the $\mathrm{TiO}_{2}$ phases

At all temperatures (Fig. 6) and pressures (Fig. 7), rutile is more stable than anatase. This has been confirmed by thermodynamic studies [5, 9, 76, 148, 152], which show that negative pressures would be required for anatase to be more stable than rutile [2]. The transformation to rutile thus is irreversible.

Table 3 gives the reported standard-state thermodynamic data for the anatase to rutile phase transformation.

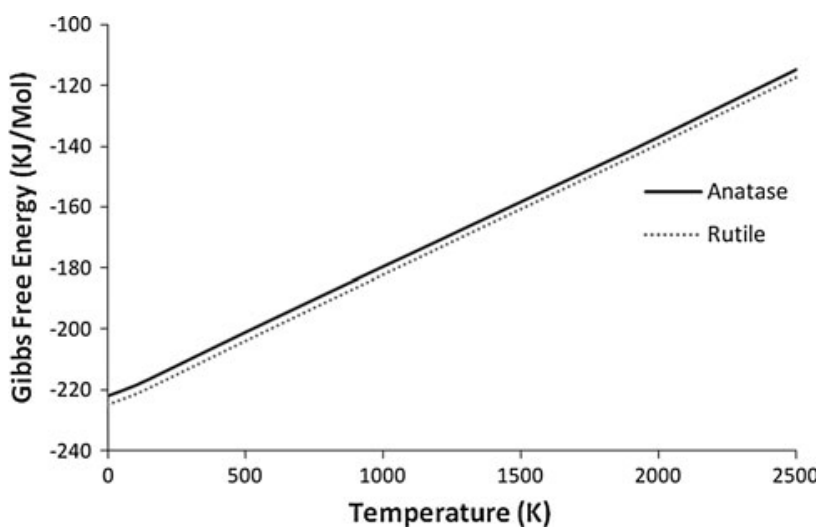

Fig. 6 Plot of Gibbs free energy of anatase and rutile versus temperature [153] 


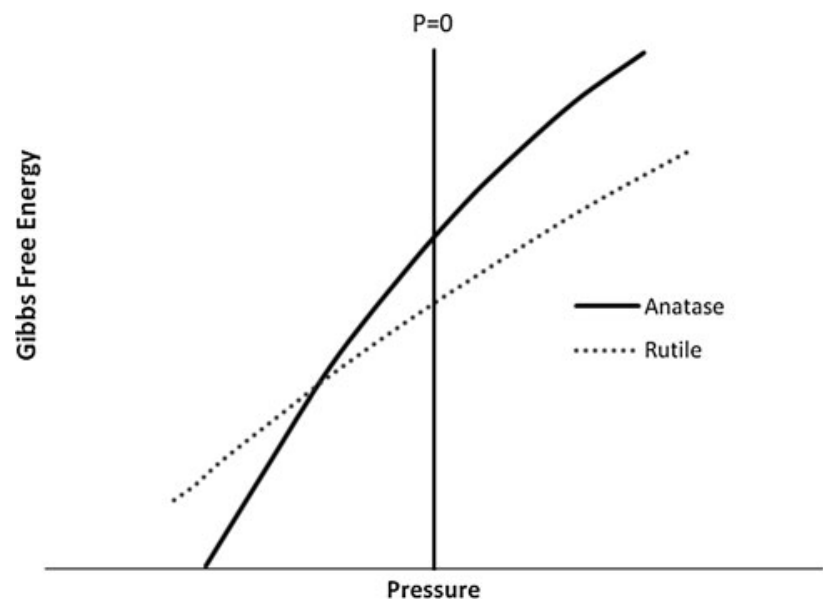

Fig. 7 Schematic plot of Gibbs free energy versus pressure (assumed to be at room temperature) [2]
Over the last 50 years various studies involving the kinetics of the transition to rutile have reported various transition temperatures. A comprehensive survey of these reported temperatures is shown in Table 4.

Table 4 shows that there are different methods that be used to define the phase transformation temperature. As discussed previously, the temperature at which the transition is observed depends on a number of parameters and so it is not surprising that a range of values has been reported. However, assessment and consideration of these data lead to the general conclusion that fine powders of high purity show phase transformation at temperatures from $\sim 600$ to $700{ }^{\circ} \mathrm{C}$.

Excluding studies which used titania of unusually small particle size or long soak times, and studies which did not use onset temperatures as the defined transition

Table 3 Summary of thermodynamic data from literature

\begin{tabular}{lclcc}
\hline Publication year & $\Delta \mathrm{H}_{298}(\mathrm{~kJ} / \mathrm{mol})$ & $\Delta \mathrm{S}_{298}(\mathrm{~J} / \mathrm{mol} \mathrm{K})$ & $\Delta \mathrm{G}_{298}(\mathrm{~kJ} / \mathrm{mol})$ & -5.32 \\
\hline 1967 & -5.19 & 0.42 & -11.84 & {$[148]$} \\
1971 & -11.7 & 0.42 & -1.87 & {$[153]$} \\
2009 & -1.70 & 0.556 & {$[5]$} & \\
\hline
\end{tabular}

These data indicate that there remains some uncertainty about the energetics of the phase transformation

Table 4 Summary of reported temperatures for the ART

\begin{tabular}{|c|c|c|c|c|}
\hline Year & $\begin{array}{l}\text { Temp. } \\
\left({ }^{\circ} \mathrm{C}\right)^{\mathrm{a}}\end{array}$ & Fabrication details & Definition & Ref \\
\hline 1961 & 610 & Highly pure powder & Onset temperature observed by XRD after firing for $24 \mathrm{~h}$ & [113] \\
\hline 1965 & $\begin{array}{l}(1190) \\
(1138) \\
(1115)\end{array}$ & Powders from three different suppliers & Apices of DTA peaks (data not shown) & [109] \\
\hline 1968 & 610 & Commercially available reagent grade powder & $\begin{array}{l}\text { Onset temperature observed by XRD after extended firing } \\
\text { (1-5 days) }\end{array}$ & [154] \\
\hline 1995 & 390 & Sol-gel synthesised powder & Appearance of detectable rutile peak by XRD after 1 week & [123] \\
\hline 1996 & 675 & Sol-gel synthesised powder & Appearance of detectable rutile peak by XRD after 4 min & [1] \\
\hline 1997 & $\begin{array}{l}(787) \\
720\end{array}$ & Sol-gel synthesised powder & $\begin{array}{l}\text { Reported value: Apex of DTA peak } \\
\text { Corrected value: Onset of DTA peak }\end{array}$ & [155] \\
\hline 1997 & 465 & 4-6 nm particles prepared through a sol-gel method & Appearance of detectable rutile peak by XRD & [156] \\
\hline 1999 & $(616)$ & Sol-gel synthesised powder & Reported value: $50 \%$ transformation observed by XRD & [157] \\
\hline 2001 & $\begin{array}{l}(680) \\
600\end{array}$ & Sol-gel synthesised powder & $\begin{array}{l}\text { Reported value: } 50 \% \text { transformation observed by XRD } \\
\text { Onset temperature from graph }\end{array}$ & {$[82]$} \\
\hline 2001 & 600 & Sol-gel synthesised powder & Appearance of detectable rutile peak by XRD & [108] \\
\hline 2002 & $\begin{array}{l}(700) \\
600\end{array}$ & Sol-gel synthesised powder & $\begin{array}{l}50 \% \text { transformation observed by XRD } \\
\text { Appearance of detectable rutile peak by XRD }\end{array}$ & [124] \\
\hline 2005 & $600-700$ & $\begin{array}{l}\text { Highly pure nanocrystals synthesised fromTiCl }{ }_{4} \\
\text { Sol-Gel }\end{array}$ & Appearance of detectable rutile peak by XRD & [99] \\
\hline 2007 & $(900)$ & Sol-gel synthesised powder & Reported value: apex of broad DTA peak (data not shown) & [158] \\
\hline
\end{tabular}

${ }^{a}$ Data in parenthesis do not correspond to the onset of the transformation 


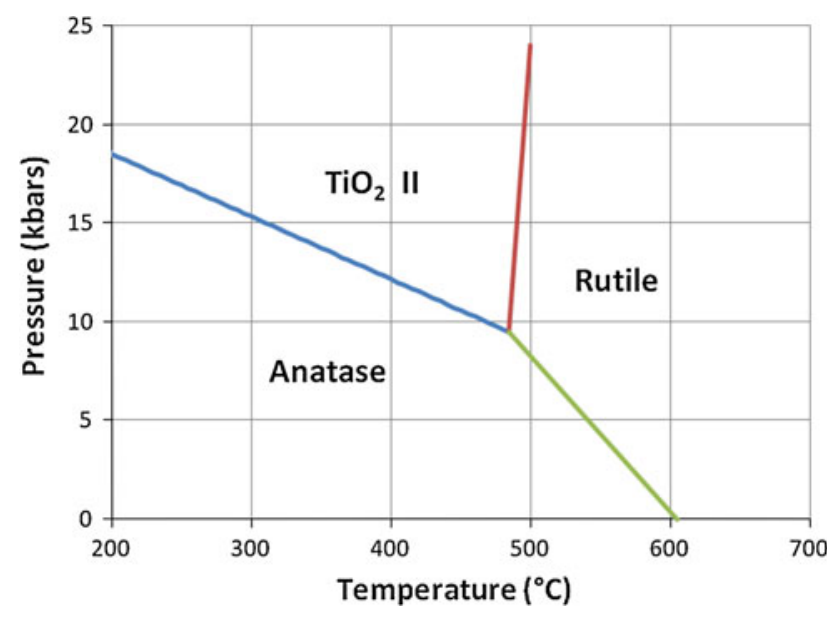

Fig. 8 Reaction boundaries of phase transitions in $\mathrm{TiO}_{2}$ [2]

temperatures, it can be seen that the reported transition onset temperatures, as determined by XRD, appear to converge around $600{ }^{\circ} \mathrm{C}$. Although it is difficult to ascertain the intrinsic behaviour of titania, this is accepted to be the region of the onset temperature of the anatase to rutile transformation in bulk pure anatase in air [2, 7, 123, 154]. This can be seen in Fig. 8 .

The one early study from 1965 [109] that reported anomalously high temperatures may have obtained these results owing to the use of powders contaminated with impurities that inhibit the phase transformation, as discussed subsequently, the use of the differential thermal analysis (DTA) peak apices rather than the onsets, and/or the use of very high heating rates.

The data in Table 4 suggest that DTA analysis yields higher transformation temperatures than XRD analysis. This probably is a result of the sigmoidal form of the kinetics curve, as shown subsequently. That is, the phase transformation commences slowly at an onset temperature of $\sim 600{ }^{\circ} \mathrm{C}$ and so it is more likely that the exotherm maximum (viz., the apex) is observed later in the phase transformation process, when the transformation rate is greatest; the rate of transformation subsequently decreases along with the corresponding latent heat as anatase converts to rutile. Despite the potential uncertainties, DTA peak apices can be considered to be applicable for comparative analysis of the phase transformation.

The assessment of DTA data must be done with care since the curves and their interpretation can be influenced significantly by experimental conditions that can cause shifts to lower temperatures: (1) a slow heating rate results in peak broadening, which lowers the onset temperature; (2) a slow heating rate also causes the entire peak to shift; (3) fine particle size shifts and narrows the entire peak; and (4) the static enclosed atmosphere induces a slightly reducing atmosphere, which enhances oxygen vacancy formation in oxides.
Rao [113] carefully examined the kinetics of the phase transformation, based on a soak of $24 \mathrm{~h}$ and XRD analysis, using very pure powders and fit the data to an Arrhenius relation. The rate of transformation decreased with temperature to a practical limit $610 \pm 10{ }^{\circ} \mathrm{C}$, at which point the transformation became immeasurably slow. Despite the age of this study, it is consistent with later studies [154, 157, 159, 160].

Since rutile is the equilibrium phase $[2,7,9,20,76,113$, $148,152]$, the presence of anatase demonstrates that these studies cannot represent equilibrium conditions, which normally employ phase diagrams for illustration. Dachille et al. [154] reported what was considered to be an pressure-temperature diagram approximating equilibrium for $\mathrm{TiO}_{2}$, which is shown in Fig. 8. The key observation of these data is the apparent anatase to rutile phase transformation conditions of $605{ }^{\circ} \mathrm{C}$ at $1 \mathrm{~atm}(101 \mathrm{kPa})$ pressure, which is quite similar to the values indicated in Table 4 .

Jamieson and Olinger [2] subsequently qualified the description of this diagram by describing the phase boundaries as reaction boundaries. Current practice is to refer to functional diagrams such as these as behavioural diagrams.

Although it is widely accepted that rutile cannot be transformed to anatase. It has been suggested that at high pressures rutile can transform to the $\alpha-\mathrm{PbO}_{2}$ structured $\mathrm{TiO}_{2}$ II polymorph $[12,161]$. This behaviour is outlined by the inferred behavioural diagram shown in Fig. 9, which is derived from mineralogical samples exposed to high pressures in the earth's crust.

Kinetics of the anatase to rutile phase transformation

For the transformation of anatase to rutile to proceed at a measureable rate, sufficient thermal energy is required to facilitate the rearrangement of atoms. As described above, it is likely that, for typical bulk titania powders (i.e., not nanoparticles), this energy requirement is reached at $\sim 600-700{ }^{\circ} \mathrm{C}$ in air in the absence of dopants or impurities,

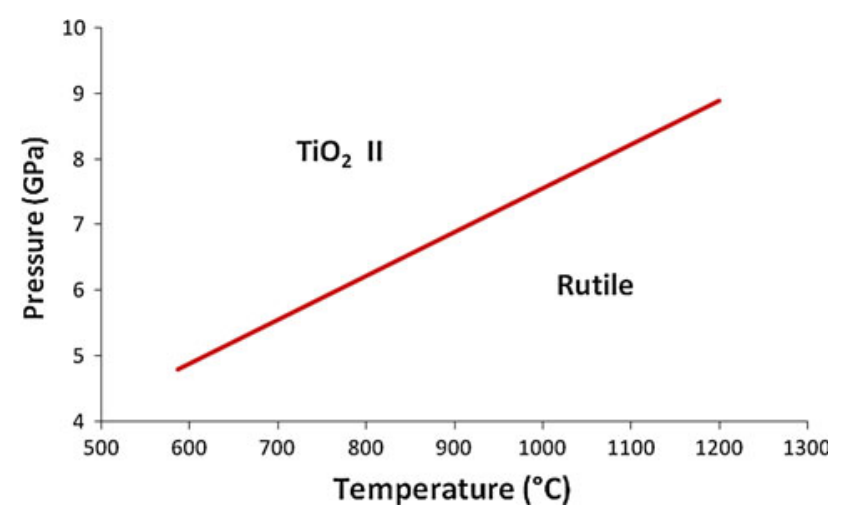

Fig. 9 Proposed behavioural diagram of the transformation of rutile to $\mathrm{TiO}_{2}$ II $[12,161]$ 
although this is subjective since impurities are always present at a finite level. As will be discussed in detail subsequently, the transformation can be enhanced or impeded by influencing the rearrangement of the atoms in the anatase and rutile lattices. It is perceived widely that the most important factor affecting the phase transformation is the presence and amount of defects on the oxygen sublattice, viz., $\mathrm{TiO}_{2-x}[67,157,162,163]$. Ease of rearrangement and transformation are enhanced by relaxation (lessening of structural rigidity) of the large oxygen sublattice through the increased presence of oxygen vacancies [109, 164, 165].

This effect has been shown through firing in different atmospheres, where neutral or reducing conditions of low oxygen partial pressure generally greatly enhance the anatase to rutile transformation $[3,67,166]$, although contrary effects have been reported as vacuum conditions have been observed to slow the phase transformation [109]. This could be a result of reduced heat transfer because vacuum conditions give lower convective heat transfer than air. The promotion of the phase transformation through the use of a reducing atmosphere is considered to be due largely to the increased levels of oxygen vacancies during heating in such atmospheres.

Figure 10 shows the effects of different experimental conditions on the kinetics of the anatase to rutile transformation in four different samples. Although these data are limited, the interpretations of the trends are straightforward:

Sample a: Doping with $\mathrm{Fe}_{2} \mathrm{O}_{3}$ (assuming substitution of $\mathrm{Ti}^{4+}$ by $\mathrm{Fe}^{3+}$ ) in a reducing atmosphere can increase the levels of oxygen vacancies by three potential mechanisms: (1) the maintenance of

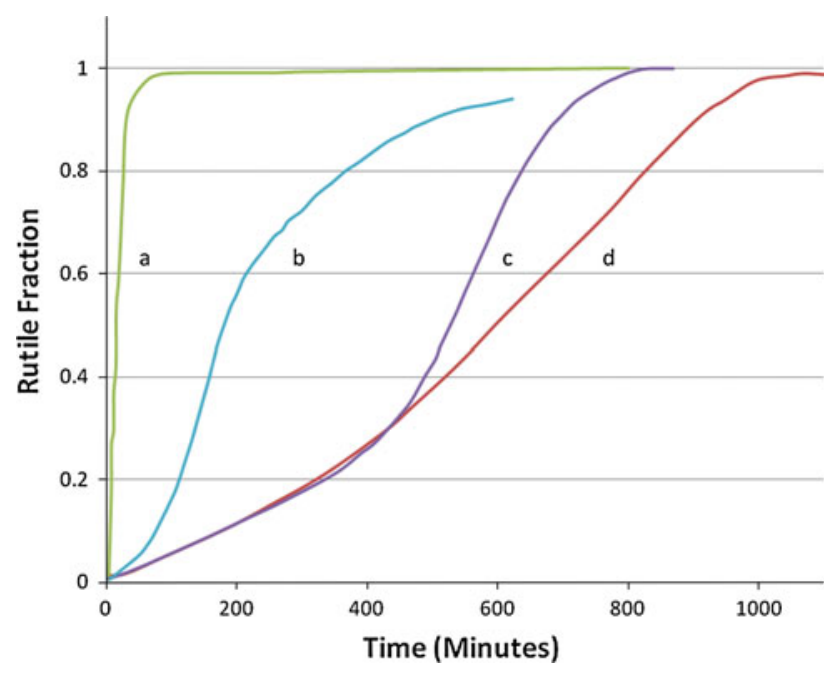

Fig. 10 Known time-transformation curves of various titania samples. $a \mathrm{Fe}_{2} \mathrm{O}_{3}$-doped titania fired in a reducing atmosphere at $1000{ }^{\circ} \mathrm{C}$ [167]. $b$ Undoped titania powder fired in air at $1050{ }^{\circ} \mathrm{C}$ [109]. $c$ $\mathrm{MnO}_{2}$-doped titania fired in air at $945{ }^{\circ} \mathrm{C}$ [164]. $d$ Undoped titania fired in air at $945^{\circ} \mathrm{C}$ [164] charge balance; (2) spontaneous reduction $\mathrm{Fe}_{2} \mathrm{O}_{3}$ to $\mathrm{Fe}_{3} \mathrm{O}_{4}$ or $\mathrm{FeO}$, which are thermodynamically stable at temperatures as low as $400{ }^{\circ} \mathrm{C}$ and low oxygen partial pressures [168]; and (3) reduction of $\mathrm{TiO}_{2}$ to $\mathrm{TiO}_{2-x}$

Samples $\mathrm{b}$ and $\mathrm{d}$ : Assuming that powders used in these two studies are similar, the only difference is the temperature. If this comparison is valid, then it is clear that the phase transformation is accelerated with the use of the higher temperature, which is as expected

Samples c and d: Doping with $\mathrm{MnO}_{2}$, while suggesting that no effect on oxygen vacancy formation should be observed, actually is similar to $\mathrm{Fe}_{2} \mathrm{O}_{3}$ because $\mathrm{Mn}^{4+}$ reduces spontaneously in air to $\mathrm{Mn}^{3+}$ and then $\mathrm{Mn}^{2+}$, with the transformation's nearcompletion by $\sim 450{ }^{\circ} \mathrm{C}[169]$. Again, the assumption of substitution of $\mathrm{Ti}^{4+}$ by $\mathrm{Mn}^{3+}$ and $\mathrm{Mn}^{2+}$ requires the generation of oxygen vacancies

\section{Effects of impurities and dopants on the anatase to rutile phase transformation}

\section{Dopant effects}

Many studies of photocatalysis by $\mathrm{TiO}_{2}$ have attempted to utilise dopants in order to improve the photocatalytic activity. In general, the role of dopants is considered to be:

- Reduction of the band gap in titania $[18,151]$

- Introduction of mid-gap states $[56,163]$

- Improvement in charge carrier separation $[68,73]$

- Increase in the levels of surface-adsorbed species (e.g., hydroxyl radicals) [43]

It often is not appreciated that all titania is contaminated with some levels of impurities. The presence of unintentional impurities or intentional dopants has a strong effect on the kinetics of the anatase to rutile transition [170]. Variable results have been reported in the sense that dopants can have the effect of hindering or enhancing the transition to rutile. In the case of substitutional solid solution formation, dopant ions can enter the anatase lattice and influence the level of oxygen vacancies, thereby promoting or inhibiting the transformation to rutile. In the case of interstitial solid solution formation, lattice constraint may result in destabilisation or stabilisation, depending on size, valence, and content effects, again promoting or inhibiting the transformation. 
If the solubility limit for impurities or dopants is exceeded, then their precipitation can facilitate the phase transformation through heterogeneous nucleation $[67,171]$.

\section{Cationic dopants}

Numerous cationic dopants have been investigated in terms of their effect on the kinetics of the anatase to rutile transition. It has been suggested that cations of small radii and low valence accelerate the transition to rutile owing to the increase in oxygen vacancies that result from the assumed substitution of $\mathrm{Ti}^{4+}$ ions with cations of lower valences [43, 109, 157, 164, 165]. Charge neutrality thus requires an increase in the level of oxygen vacancies and/or the formation of Ti interstitials of lower valence [82, 172]. Conversely, when cations of valence higher than 4 are assumed to substitute for $\mathrm{Ti}$ ions on the anatase lattice, this gives rise to the annihilation of existing oxygen vacancies and the formation of $\mathrm{Ti}$ interstitials of the same or lower valence. These processes can be viewed in light of the inertia to alteration (through ionic transport) of the relatively large and rigid oxygen sublattice, which largely determines the structural stability and the capacity to reorganise the chemical bonds to form rutile. From these considerations, the assumption of substitutional solid solubility leads to the conclusion that small cations of low valence $(<4)$ should promote the anatase to rutile transformation and large cations of high valence $(>4)$ should inhibit it.

However, the assumption of substitutional solid solubility may be incorrect and interstitial solid solubility occurs. In this case, the insertion of a cation results in constraint of the required lattice contraction largely in the $c$ direction upon the transformation from anatase to rutile [173], without apparent effect on the charge neutrality. Although there are reports of interstitial stabilisation of the titania lattice and consequent inhibition of the transformation [155, 174, 175], there do not appear to be any reports of destabilisation (from structural instability) and consequent promotion of the transformation.

A comprehensive summary of the cationic dopant effects from the literature sources is given in Table 5.

The effects of the dopant cations in terms of the valences and ionic radii are illustrated in Fig. 11. These data have been compiled on the basis of the following conditions:

- Shannon-Prewitt ionic radii in sixfold coordination [173], which is the case for both anatase and rutile [14], were used.

- The most common valence for each cation has been used, without regard to oxidation-reduction effects (except as noted below).

- The valences for Mn, Fe, and Co are assumed to be 2 as these species would be likely to reduce spontaneously
Table 5 List of dopants in titania

\begin{tabular}{|c|c|}
\hline \multicolumn{2}{|c|}{ Phase transformation inhibitors } \\
\hline Cation & Dopant phases used \\
\hline $\mathrm{Al}$ & $\begin{array}{l}\mathrm{AlOOH}[176], \mathrm{Al}\left(\mathrm{OC}_{4} \mathrm{H}_{9}\right)_{3}[108], \mathrm{AlCl}_{3}[119,177] \\
\quad \mathrm{Al}\left(\mathrm{NO}_{3}\right)_{3}[175]\end{array}$ \\
\hline $\mathrm{Au}$ & $\mathrm{HAuCl}_{4}[178]$ \\
\hline $\mathrm{B}$ & $\mathrm{BCl}_{3}[120]$ \\
\hline $\mathrm{Ba}$ & $\mathrm{Ba}\left(\mathrm{NO}_{3}\right)_{2}[157]$ \\
\hline $\mathrm{Ca}$ & $\mathrm{Ca}\left(\mathrm{NO}_{3}\right)[157]$ \\
\hline $\mathrm{Ce}$ & $\mathrm{CeO}_{2}[179]$ \\
\hline Dy & $\mathrm{Dy}_{2} \mathrm{O}_{3}[180]$ \\
\hline $\mathrm{Eu}$ & $\mathrm{EuCl}_{3}[70] \mathrm{Eu}_{2} \mathrm{O}_{3}[56]$ \\
\hline $\mathrm{Er}$ & $\mathrm{Er}\left(\mathrm{NO}_{3}\right)_{3}[157], \mathrm{Er}_{2} \mathrm{O}_{3}[181]$ \\
\hline $\mathrm{Fe}$ & $\mathrm{FeCl}_{2}[171]$ \\
\hline Ho & $\mathrm{Ho}_{2} \mathrm{O}_{3}[181]$ \\
\hline $\mathrm{La}$ & $\mathrm{La}\left(\mathrm{NO}_{3}\right)_{3}[157,182], \mathrm{La}_{2} \mathrm{O}_{3}[181]$ \\
\hline $\mathrm{Mn}$ & $\mathrm{Mn}\left(\mathrm{NO}_{3}\right)_{2}[183],<1 \mathrm{~mol} \% \mathrm{Mn}\left(\mathrm{CH}_{3} \mathrm{COO}\right)_{2}[184]$ \\
\hline $\mathrm{Nb}$ & $\mathrm{NbCl}_{5}[185]$ \\
\hline $\mathrm{Nd}$ & $\mathrm{Nd}_{2} \mathrm{O}_{3}[181]$ \\
\hline $\mathrm{P}$ & $\mathrm{PO}_{4} \mathrm{H}_{2} \mathrm{~K}[118], \mathrm{POCl}_{3}[120]$ \\
\hline $\mathrm{Si}$ & $\mathrm{Si}\left(\mathrm{OC}_{2} \mathrm{H}_{5}\right)_{4}[82,108,128,175], \mathrm{SiCl}_{4}(\mathrm{~g})[120]$ \\
\hline $\mathrm{Sm}$ & $\mathrm{SmCl}_{3}[70], \mathrm{Sm}_{2} \mathrm{O}_{3}[181]$ \\
\hline $\mathrm{Sr}$ & $\mathrm{Sr}\left(\mathrm{NO}_{3}\right)_{2}[157]$ \\
\hline $\mathrm{Tb}$ & $\mathrm{Tb}_{4} \mathrm{O}_{7}[181]$ \\
\hline $\mathrm{Tm}$ & $\mathrm{Tm}_{2} \mathrm{O}_{3}[181]$ \\
\hline Y & $\mathrm{Y}\left(\mathrm{NO}_{3}\right)_{3}[157], \mathrm{Y}_{2} \mathrm{O}_{3}[181]$ \\
\hline $\mathrm{Zr}$ & $\mathrm{Zr}\left(\mathrm{OC}_{3} \mathrm{H}_{7}\right)_{4}[108,186], \mathrm{Zr}\left(\mathrm{SO}_{4}\right)_{2}[66], \mathrm{ZrOCl}_{2}$ \\
\hline
\end{tabular}

Phase transformation promoters

\begin{tabular}{|c|c|}
\hline Cation & Dopant phases used \\
\hline $\mathrm{Al}$ & $\mathrm{AlCl}_{3}(\mathrm{~g})[187]$ \\
\hline $\mathrm{Cd}$ & $\mathrm{CdO}[165]$ \\
\hline $\mathrm{Co}$ & $\mathrm{CoO}[165]$ \\
\hline $\mathrm{Cr}$ & $\mathrm{CrCl}_{3}[185]$ \\
\hline $\mathrm{Cu}$ & $\mathrm{CuO}[109,127,164]$ \\
\hline $\mathrm{Fe}$ & $\mathrm{Fe}[41], \mathrm{Fe}_{2} \mathrm{O}_{3}[127,164,167]$ \\
\hline $\mathrm{Li}$ & $\operatorname{LiF}[118]$ \\
\hline $\mathrm{Mn}$ & $\mathrm{MnO}_{2}[164,165], \mathrm{Mn}\left(\mathrm{NO}_{3}\right)_{2}[183,188], \mathrm{MnSO}_{4}[67]$ \\
\hline $\mathrm{Na}$ & $\mathrm{NaF}[165]$ \\
\hline $\mathrm{Ni}$ & $\mathrm{Ni}\left(\mathrm{NO}_{3}\right)_{2}[128] \mathrm{Ni}\left(\mathrm{CH}_{3} \mathrm{COO}\right)_{2}[189]$ \\
\hline $\mathrm{Sb}$ & $\mathrm{Sb}_{2} \mathrm{O}_{3}[190]$ \\
\hline Sn & $\mathrm{SnO}_{2}[158], \mathrm{SnCl}_{2}[149]$ \\
\hline $\mathrm{V}$ & $\mathrm{VO}_{2}[128], \mathrm{V}_{2} \mathrm{O}_{5}[191]$ \\
\hline $\mathrm{Zn}$ & $\mathrm{ZnO}[165]$ \\
\hline
\end{tabular}

to show this valence state upon heating at temperatures approaching the ART temperature [167, 169, 192].

- Inhibition or promotion of the phase transformation is reported on the basis of the effects described in the literature sources given in Table 5 . 


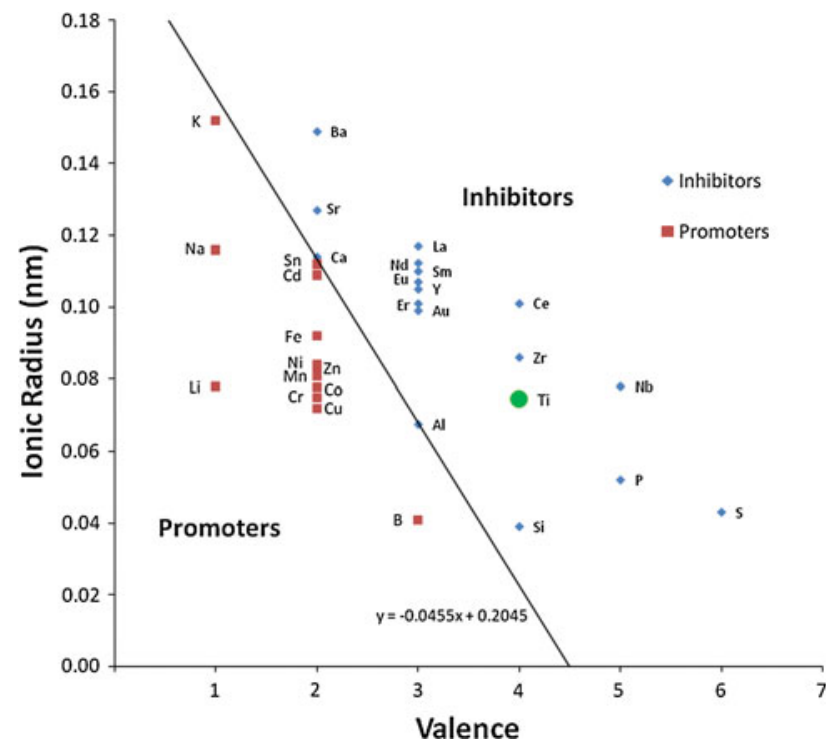

Fig. 11 Comprehensive valence/radius plot of anatase to rutile transformation, categorising inhibiting and promoting dopants, based on the published reports in Table 5

- In the case of cations for which contradictory effects are reported ( $\mathrm{Mn}$ and $\mathrm{Fe}$ ), the most common finding was used.

The formula of the boundary line is

$y=-0.0455 x+0.2045$

where $x$ is the valence and $y$ is the ionic radius.

The data shown in Fig. 11 should be considered indicative owing to the potential presence of impurities, the vagaries in the reported experimental procedures, and the assumptions stated above. For example, in 1960, Iida and Ozaki [127] reported findings which contrary to those of many other studies in that sodium was observed to inhibit the transformation. This seems likely to be due to the use of sodium in the form of a salt which only decomposed at $900{ }^{\circ} \mathrm{C}$.

\section{Anionic dopants}

Anions doping is of interest owing to its potential to improve the photocatalytic performance of $\mathrm{TiO}_{2}$ [18]. There is limited discussion in the literature regarding the effects of foreign anions on the anatase to rutile transformation, probably owing to the uncertainty of whether doping actually occurs. It is reasonable to assume that doping by anions results in the filling of oxygen vacancies. The inhibition or promotion of the phase transformation is likely to depend on size and charge effects, which are as follows:

$\mathrm{Cl}^{1-}>\mathrm{N}^{3-}>\mathrm{O}^{2-}>\mathrm{F}^{1-}$
Nitrogen doping

Size effects: according to Hume-Rothery [193], metal ion dopants whose ionic radii are within $15 \%$ of that of the host lattice, which typically is closest packed, can show appreciable solubility. It is assumed that the oxygen sublattice, which also is closest packing, can be considered similar to that of most metals. Unfortunately, the only comparable ionic radii for the two anions is for fourfold coordination [S-P], but the ionic radii of anions vary little across the different negative valences. Since nitrogen is only $\sim 6 \%$ larger than oxygen, then substitution of nitrogen on the oxygen sublattice is possible. Hence, nitrogen is unlikely to destabilise the lattice and so would be expected to be an inhibitor of the phase transformation.

Charge effects: if $\mathrm{N}^{3-}$ substitutes for $\mathrm{O}^{2-}$, then the impossibility of establishing charge balance through the formation of $\mathrm{Ti}^{5+}$ means that oxygen must be removed from the lattice. Since the inclusion of two nitrogen ions is balanced by the removal of three oxygen ions, then the level of oxygen vacancies increases, the lattice can be expected to be destabilised, and the phase transformation is promoted. Accordingly, it has been reported that nitrogen doping increases the level of oxygen vacancies in anatase $[117,162]$ although there do not appear to be any reports on the effect of chemical nitrogen (rather than physical nitrogen, as in the furnace atmosphere) on the phase transformation.

\section{Fluorine doping}

Size effects: fluorine in both fourfold and sixfold coordinations is $\sim 6 \%$ smaller than oxygen, then fluorine replacement on the oxygen sublattice is possible. Hence, fluorine would be expected to be an inhibitor.

Charge effects: if $\mathrm{F}^{1-}$ substitutes for $\mathrm{O}^{2-}$, then anion charge balance requires the inclusion of two fluorine ions for each oxygen. This is extremely unlikely from size considerations. The other alternative is the inclusion of one fluorine ion in an oxygen vacancy site and the resultant reduction of the associated $\mathrm{Ti}^{4+}$ or $\mathrm{Ti}^{3+}$, which would remain on the cation sublattice; the insertion of fluorine would decrease the level of oxygen vacancies. Further, the expansion of the titanium ionic radius upon reduction [s-p] would cause lattice constraint. Both of these mechanisms would be expected to inhibit the phase transformation. In agreement, fluorine has been reported to inhibit the phase transformation [64, 90].

The annihilation of an oxygen vacancy by fluorine doping is described by Eq. 7:

$\mathrm{F}^{-}+2 \mathrm{Ti}^{3+}+3 \mathrm{O}^{2-}+\square \mathrm{a} \rightarrow \mathrm{Ti}^{4+}+\mathrm{Ti}^{3+}+3 \mathrm{O}^{2-}+\mathrm{F}^{-}$

Here, $\square$ a denotes an anion vacancy. 


\section{Chlorine doping}

Size effects: chlorine in sixfold coordination is $\sim 33 \%$ larger than oxygen. Hence, it is very unlikely to enter (solid state) or be retained in (solution) the titania lattice.

Charge effects: in light of the above, the inclusion of two chlorine ions for one oxygen ion is extremely unlikely. For the same reason, inclusion of one chlorine and titanium reduction also is unlikely. The preceding being said, chlorine has been reported to inhibit the phase transformation $[64,90]$. Conversely, atmospheric chlorine also has been reported to promote the phase transformation [3].

\section{Valence changes}

An important issue to consider is that certain cationic dopants may exhibit more than one valence and the associated potential for reduction-oxidation reactions [165, 169]. These can result in an increase in the level of oxygen vacancies (promotion of the phase transformation through increase in lattice relaxation) and/or the formation of $\mathrm{Ti}^{3+}$ interstitial (inhibition of the phase transformation through lattice constraint). The fact that $\mathrm{Al}^{3+}$ has only a single valence may explain why it inhibits the phase transformation as opposed to $\mathrm{Fe}^{3+}$, which promotes the phase transformation, although being of similar size and valence to $\mathrm{Al}^{3+}$.

This can be attributed to its likely valence change during heating.

Iron can undergo reduction creating an oxygen vacancy by the reaction in Eq. 8.

$2 \mathrm{Fe}^{3+}+\mathrm{O}^{2-} \rightarrow 2 \mathrm{Fe}^{2+}+\square \mathrm{a}+\frac{1}{2} \mathrm{O}_{2}$

Here, $\square$ a denotes an anion vacancy.

In the $\mathrm{TiO}_{2}$ lattice the anatase to rutile phase transformation will be promoted by the formation of oxygen vacancies by the reduction of dopant iron $3+$ following the reaction shown in Eq. 9:

$$
\begin{aligned}
\mathrm{Fe}^{3+}+\mathrm{Ti}^{4+}+2 \mathrm{O}^{2-} \rightarrow & \left(\mathrm{Fe}^{2+}+\mathrm{O}^{2-}+\square \mathrm{a}\right) \\
& +\mathrm{Ti}_{\text {interstitial }}^{3+}+\frac{1}{2} \mathrm{O}_{2}
\end{aligned}
$$

The anion vacancy, $\square \mathrm{a}$, enhances the phase transformation.

In the case of aluminium doping of $\mathrm{TiO}_{2}$, the reaction is

$$
\begin{aligned}
\mathrm{Al}^{3+}+\mathrm{Ti}^{4+}+2 \mathrm{O}^{2-} \rightarrow & \left(\mathrm{Al}^{3+}+\frac{3}{2} \mathrm{O}^{2-}+\frac{1}{2} \square \mathrm{a}\right) \\
& +\mathrm{Ti}_{\text {interstitial }}^{3+}+\frac{1}{4} \mathrm{O}_{2}
\end{aligned}
$$

In the case of doping of $\mathrm{TiO}_{2}$ by $\mathrm{Mn}$ and its reduction from $\mathrm{Mn}^{4+}$ to $\mathrm{Mn}^{2+}$ which occurs sponatneously at temperatures above $400{ }^{\circ} \mathrm{C}$ [169] the reaction is described by the following:

$$
\begin{aligned}
\mathrm{Mn}^{4+}+\mathrm{Ti}^{4+}+2 \mathrm{O}^{2-} \rightarrow & \left(\mathrm{Mn}^{2+}+\mathrm{O}^{2-}+\square \mathrm{a}\right) \\
& +\mathrm{Ti}_{\text {interstitial }}^{4+}+\frac{1}{2} \mathrm{O}_{2}
\end{aligned}
$$

The creation of oxygen vacancies in $\mathrm{TiO}_{2}$ through valence change in $\mathrm{Fe}$ was confirmed by Heald and Weiss [167] and Genarri and Pasquevich [192] who used haematite in solid state form as a dopant. In another study, after Fe was added in a $3+$ oxidation state form and the doped $\mathrm{TiO}_{2}$ was heated in air, electron paramagnetic resistance (EPR) showed that $\mathrm{Fe}$ was present in the $2+$ oxidation state and that this promoted the phase transformation [194].

In contrast, the addition of $\mathrm{Fe}$ in the 2 valence, using $\mathrm{FeCl}_{2}$ and firing in air, resulted in inhibition of the phase transformation [171]. Mössbauer spectroscopy revealed that iron was present interstitially in the 3 valence. If the 2 valence was retained during heating, then size and charge considerations support the view that $\mathrm{Fe}^{2+}$ would be unlikely to substitute for $\mathrm{Ti}^{4+}$. Further, the oxidation of $\mathrm{Fe}^{2+}$ to $\mathrm{Fe}^{3+}$ would require the annihilation of oxygen vacancies, in reverse of reaction 8 . Hence, both of these phenomena would be expected to inhibit the phase transformation.

The preceding different outcomes from doping with the same metal highlight the importance of differentiating between the assumption of substitutional and interstitial solid solubility. Again, the same dopant in substitutional form may increase the oxygen vacancy level and promote the phase transition while, in the interstitial form, may enhance lattice constraint and inhibit the phase transformation. This applies to all dopants, although the transition metals of variable valence (e.g., $\mathrm{Mn}, \mathrm{Fe}, \mathrm{Ni}$ ), are most likely to be those that show mixed effects.

In contrast, the absence of the likelihood of valence change is more straightforward. In the case of substitution of $\mathrm{Ti}^{4+}$ by $\mathrm{Al}^{3+}$, half an oxygen vacancy and a $\mathrm{Ti}^{3+}$ interstitial are created (Eq. 7), thereby promoting and inhibiting the phase transformation, respectively. Since, the inhibition of the phase transformation by aluminium doping is well known [155, 175, 195], if substitution is the mechanism, then it can be concluded that the effect of lattice constraint is greater than that of lattice relaxation. However, if $\mathrm{Al}^{3+}$ enters the lattice interstitially, then only lattice constraint results, which inhibits the phase transformation and so no information about the relative importance of the two mechanisms is provided.

\section{Predictive analysis}

Using data from the literature, it is in principle possible to make a subjective estimate of the potential effects of 
dopants for which no data are available. The four deductive considerations used to predict the effects of dopants on the anatase to rutile transition are:

- Most common valence and ionic radii of substitutional cationic dopants in conjunction with Eq. 6 and the equivalent interpolated boundary in Fig. 11.

- The potential for valence changes in dopant cations (e.g., $\mathrm{Fe}^{3+} \rightarrow \mathrm{Fe}^{2+}$ ).

- The potential for oxygen vacancy formation through reduction (e.g., C- and $\mathrm{N}$-doping).

- The known effects of anionic dopants (e.g., $\mathrm{F}^{-}$and $\mathrm{Cl}^{-}$).
A summary of the reported and predicted effects of dopants on the phase transformation is given as follows.

Inhibitors

See Fig. 12.

Promoters

See Fig. 13.
Fig. 12 Experimental and predicted inhibition of anatase to rutile transformation based on the preceding four considerations

Fig. 13 Experimental and predicted promotion of anatase to rutile transformation based on the preceding four considerations
Dopant experimentally observed to inhibit the transformation of anatase to rutile

Dopant experimentally observed to inhibit the phase transformation under certain conditions (mixed effect)

Dopant predicted to inhibit the transformation of anatase to rutile

\begin{tabular}{|c|c|c|c|c|c|c|c|c|c|c|c|c|c|c|c|c|c|}
\hline $\mathbf{H}$ & & & & & & & & & & & & & & & & & $\mathbf{H e}$ \\
\hline $\mathbf{L i}$ & $\mathbf{B e}$ & & & & & & & & & & & B & $\mathrm{C}$ & $\mathbf{N}$ & O & $\mathbf{F}$ & $\mathrm{Ne}$ \\
\hline $\mathbf{N a}$ & Mg & & & & & & & & & & & $\mathbf{A l}$ & $\mathbf{S i}$ & $\mathbf{P}$ & $\mathbf{S}$ & $\mathrm{Cl}$ & $\mathbf{A r}$ \\
\hline $\mathbf{K}$ & $\mathrm{Ca}$ & Sc & $\mathbf{T i}$ & $\mathbf{V}$ & $\mathrm{Cr}$ & $7 m$ & 50 & Co & 51 & $\mathrm{Cu}$ & $\mathbf{Z n}$ & $\mathbf{G a}$ & Ge & As & $\mathrm{Se}$ & $\mathrm{Br}$ & $\mathbf{K r}$ \\
\hline $\mathbf{R b}$ & $\mathrm{Sr}$ & $\mathbf{Y}$ & $\mathrm{Zr}$ & $\mathbf{N b}$ & Mo & Tc & $\mathbf{R u}$ & $\mathbf{R h}$ & Pd & Ag & Cd & In & Sn & Sb & $\mathbf{T e}$ & I & $\mathbf{X e}$ \\
\hline Cs & $\mathrm{Ba}$ & La & Hf & $\mathbf{T a}$ & $\mathbf{W}$ & $\mathbf{R e}$ & Os & Ir & $\mathbf{P t}$ & $\mathbf{A u}$ & Hg & $\mathbf{T l}$ & $\mathbf{P b}$ & $\mathbf{B i}$ & Po & At & $\mathbf{R n}$ \\
\hline Fr & $\mathbf{R a}$ & Ac & $\mathbf{R f}$ & Db & Sg & Bh & Hs & Mt & & & & & & & & & \\
\hline
\end{tabular}

\begin{tabular}{|c|c|c|c|c|c|c|c|c|c|c|c|c|c|}
\hline Ce & Pr & Nd & Pm & Sm & Eu & Gd & Tb & Dy & Ho & Er & Tm & Yb & Lu \\
\hline Th & Pa & U & Np & Pu & Am & Cm & Bk & Cf & Es & Fm & Md & No & Lr \\
\hline
\end{tabular}

Dopant experimentally observed to promote the transformation of anatase to rutile

Dopant experimentally observed to promote the phase transformation under certain conditions (mixed effect)

Dopant predicted to promote the transformation of anatase to rutile

\begin{tabular}{|c|c|c|c|c|c|c|c|c|c|c|c|c|c|c|c|c|c|}
\hline $\mathbf{H}$ & & & & & & & & & & & & & & & & & He \\
\hline $\mathbf{L i}$ & $\mathbf{B e}$ & & & & & & & & & & & B & $\mathbf{C}$ & $\mathbf{N}$ & O & $\mathbf{F}$ & $\mathrm{Ne}$ \\
\hline $\mathrm{Na}$ & $\mathrm{Mg}$ & & & & & & & & & & & Al & $\mathbf{S i}$ & $\mathbf{P}$ & $\mathbf{S}$ & $\mathrm{Cl}$ & $\mathbf{A r}$ \\
\hline $\mathbf{K}$ & $\mathbf{C a}$ & Sc & $\mathbf{T i}$ & $\mathbf{V}$ & $\mathrm{Cr}$ & In & 1 & Co & 45 & $\mathrm{Cu}$ & $\mathrm{Zn}$ & $\mathbf{G a}$ & Ge & As & Se & $\mathrm{Br}$ & $\mathbf{K r}$ \\
\hline $\mathbf{R b}$ & $\mathbf{S r}$ & $\mathbf{Y}$ & $\mathbf{Z r}$ & $\mathrm{Nb}$ & Mo & Tc & $\mathbf{R u}$ & $\mathbf{R h}$ & Pd & Ag & Cd & In & Sn & $\mathbf{S b}$ & Te & I & $\mathbf{X e}$ \\
\hline Cs & $\mathbf{B a}$ & La & Hf & $\mathbf{T a}$ & W & $\mathbf{R e}$ & Os & Ir & $\mathbf{P t}$ & $\mathbf{A u}$ & $\mathrm{Hg}$ & Tl & $\mathrm{Pb}$ & $\mathbf{B i}$ & Po & $\mathbf{A t}$ & $\mathbf{R n}$ \\
\hline Fr & $\mathbf{R a}$ & Ac & $\mathbf{R f}$ & Db & $\mathrm{Sg}$ & Bh & Hs & Mt & & & & & & & & & \\
\hline
\end{tabular}

\begin{tabular}{|c|c|c|c|c|c|c|c|c|c|c|c|c|c|}
\hline Ce & Pr & Nd & Pm & Sm & Eu & Gd & Tb & Dy & Ho & Er & Tm & Yb & Lu \\
\hline Th & Pa & U & Np & Pu & Am & Cm & Bk & Cf & Es & Fm & Md & No & Lr \\
\hline
\end{tabular}




\section{Carbon doping}

Carbon is an attractive dopant for titanium dioxide photocatalysts as it has been reported to reduce the band gap and improve photocatalytic performance in anatase [20]. Carbon $4+$ has an ionic radius of $0.03 \mathrm{~nm}$, which places it close to the line of Eq. 6, making a prediction of its effects on the anatase to rutile transformation based on valence/ size considerations uncertain. Moreover, there is an apparent absence of reported data regarding the effects of carbon on the transformation of anatase to rutile. This is a result of the likelihood of carbon oxidation at temperatures below the anatase to rutile phase transformation temperature. However, carbon is a very strong reducing agent and, when retained during firing in an inert atmosphere, it would be likely to enhance the transformation to rutile through the formation of oxygen vacancies. Further, the oxygen-deficient atmosphere created through the use of an inert gas overpressure also would enhance the transformation to rutile through defect formation. In the extreme case, a stable carbide could form by reaction. Effectively, all of these are reduction reactions that take place to different degrees, as indicated:

Defect Formation : $\mathrm{TiO}_{2}+x \mathrm{C} \rightarrow \mathrm{TiO}_{2-x}+x \mathrm{CO}$

Suboxide Formation : $\mathrm{TiO}_{2}+\mathrm{C} \rightarrow \mathrm{TiO}+\mathrm{CO}$

Carbide Formation : $\mathrm{TiO}_{2}+2 \mathrm{C} \rightarrow \mathrm{TiC}+\mathrm{CO}_{2}$

Consequently, carbon is predicted to promote the phase transformation, as shown in Fig. 13.

It has been reported that nitrogen doping increases the levels of oxygen vacancies in anatase [117, 162], so it is likely to promote the transition to rutile. However, this has not been reported. In light of the preceding, nitrogen also is predicted promote the phase transformation in Fig. 13.

\section{Importance of doping methods}

The preparation technique of doped anatase is critically important because it impacts on the degree of equilibration achieved. There are three general methods by which dopants can be combined with anatase: point contact, surface contact, and molecular level mixing. These are listed below in order of decreasing diffusion distance required for the dopant ions in order to enter the anatase lattice:

- Dry mixing: this involves the blending of dry powders of anatase and dopant-bearing phases, such as oxides. Both large particle sizes and inhomogeneous mixing are associated with increased diffusion distances.

- Wet impregnation: this method involves mixing dry anatase powder with a dopant-bearing solution, such as dissolved salts or metal-alkoxides [67, 188].
- Molecular-level mixing: this method offers the most intimate level of association and involves mixing of a soluble titanium-bearing compound, typically an organometallic, such as titanium isopropoxide, with a soluble dopant-bearing compounds in an organic or aqueous solution. This level of mixing often is obtained through the use of doped sol-gels or co-precipitation.

Doping methods that involve larger diffusion distances for the dopant compounds to enter the titania lattice may diminish the inhibiting or promoting effect of the dopant on the anatase to rutile phase transformation since this may take place before the dopant has entered the anatase lattice.

\section{Oxide dopants}

Alumina, silica, and zirconia and have been used to stabilise anatase [66, 108, 120, 174, 196]. It has been suggested that $\mathrm{Al}, \mathrm{Si}$, and $\mathrm{Zr}$ stabilise anatase by occupying interstices, thereby distorting the anatase lattice and restricting the lattice contraction involved in the transformation to rutile [120]. Conversely, Yang and Ferreira [175] have suggested that the observed contraction in lattice parameters upon $\mathrm{SiO}_{2}$ and/or $\mathrm{Al}_{2} \mathrm{O}_{3}$ doping is evidence of solid solubility. Another study of the effects of $\mathrm{SiO}_{2}$ doping on the lattice parameter of anatase [82] also suggested that $\mathrm{Si}^{4+}$ enters substitutionally, thereby decreasing the lattice parameter of anatase (and forming interstitial $\mathrm{Ti}^{4+}$ ). Further, it is possible that the distortion of the lattice by the doping restricts the ionic rearrangement similar to that of interstitial ions. Also, the presence of undissolved $\mathrm{SiO}_{2}$, possibly as a grain boundary glassy phase, has been suggested to inhibit diffusion and reduce anatase interparticle contact, thus reducing the number of available heterogeneous nucleation sites [82].

The use of solid-state dopants introduces the scope for heterogeneous rutile nucleation at the surfaces of the dopant material. This may be the case for tin oxide which has been suggested to facilitate epitaxial growth of rutile due to its similar lattice parameters $[158,197]$. Such rutile nucleation has been reported to accelerate the transformation to rutile, causing it to take place rapidly so that coarsening does not have the time to occur. This study supports the view that the grain growth typically associated with the phase transformation is not a cause but an effect.

\section{Other considerations}

Effects of firing atmosphere on the anatase to rutile transformation

Rutile is reported widely to exhibit oxygen deficiency and can be described more appropriately as having the formula 
$\mathrm{TiO}_{2-x}[163,198-200]$. Such a stoichiometry requires, in principle, the presence of titanium lattice ions, unintentional impurities, and/or intentionally added dopants of valences lower than 4 in order to maintain charge balance. This nonstoichiometry may be present in anatase as well, although this appears not to have been discussed in the literature. The oxygen vacancies in anatase can be expected to enhance the transformation to rutile owing to the facilitated rearrangement of ions.

In contrast to the use of dopants, the atmosphere used during heating of anatase may affect the probability and kinetics of the transformation to rutile. That is, inert (viz., noble gases) or reducing atmospheres (viz., hydrogen) can be expected to increase the number of oxygen vacancies in the anatase lattice (relative to heating in air), thereby promoting the transformation to rutile. Conversely, heating in air or $\mathrm{O}_{2}$ can be expected to inhibit the transformation owing to the filling of vacancies. These effects have been observed in various reports [67, 109, 167, 192], typically through reporting the transformation temperature.

\section{Formation of crystalline $\mathrm{TiO}_{2}$ from solutions}

Alternative methods of obtaining rutile, anatase, or brookite directly from solution at relatively low temperatures have been investigated using solvothermal processes [83, 94-96, 121, 197, 201-203]. These approaches involve the use of titanium-bearing solutions of varying $\mathrm{pH}$. When titanium alkoxides undergo hydrolysis, the result is agglomorated titanium hydroxide groups which are often in the form of white amorphous precipitates [46, 95, 204]. Such solutions also can be synthesised using $\mathrm{TiCl}_{4}[96,99$, $103,104,202]$ which can result in crystalline phases of high purity. The use of a low $\mathrm{pH}$ limits condensation reactions [197], imposes a repulsive charge and limits the size of these precipitates resulting in the presence of free $\left[\mathrm{Ti}(\mathrm{OH})_{x}\left(\mathrm{OH}_{2}\right)_{6-x}\right]^{(4-x)+}$ octahedra in solution [197, 201], possibly also through dissolution of amorphous particles [201]. These octahedra can then link together to give crystalline $\mathrm{TiO}_{2}$ phases. Higher $\mathrm{pH}$ levels are more conducive to the formation of amorphous titania as octahedra are not free in solution and therefore less able to link together to form a crystalline phase.

Upon heating, the manner in which $\left[\mathrm{Ti}(\mathrm{OH})_{x}\right.$ $\left.\left(\mathrm{OH}_{2}\right)_{6-x}\right]^{(4-x)+}$ octahedra join determines the crystalline phase that precipitates. If the octahedra have sufficient time to join linearly, with two edges of each octahedron's being shared (see Figs. 3, 4), the free energy is lowered resulting in the formation of the equilibrium phase rutile in the form of grains elongated in the [001] direction [201, 202]. Alternatively, if the crystallisation rate from the solution is increased, the octahedra may tend to join at right angles as there are more positions for linkage available in this manner, such crystallisation would result in anatase formation which is statistically favoured owing to the more flexible zigzag construction of this polymorph, with four edges of each octahedron's being shared (see Figs. 3, 4) [201].

Slower crystallisation will yield the rutile phase and more rapid crystallisation favours anatase. This reasoning may also explain why anatase is generally the product phase from most industrial titania manufacturing methods which tend to involve rapid crystallisation of titania through flame pyrolysis of $\mathrm{TiCl}_{4}$.

\section{Morphological effects}

The grain morphology plays an important role in photocatalytic applications of titania. Nanocrystallinity has been shown to lower the material's densification temperature and enhance its photocatalytic activity [73, 76, 110, 205]. A common goal is to inhibit the grain growth of titania during heating as this gives a higher surface area and thus improved performance.

Bulk rutile is more stable thermodynamically than anatase at all temperatures and pressures (Figs. 7, 8) owing to its lower free energy [73, 76, 105, 110, 206]. However, the lower surface energy of the anatase planes relative to those of rutile [76] cause the former to be more stable for crystallites of extremely small sizes and correspondingly high surface areas. In these cases, surface energy considerations outweigh those of bulk thermodynamics and so, for crystallites below a critical size (45 nm [170], $14 \mathrm{~nm}$ [76], and $11 \mathrm{~nm}$ [207]), anatase has a lower total (bulk and surface) free energy [73, 76, 206]. Further, the size above which rutile becomes more stable depends on stresses [76].

Despite this, it has been reported that larger anatase grains (i.e., predominantly bulk thermodynamics) transform to rutile more slowly than finer grains (i.e., predominantly surface thermodynamics). This probably is due to the lower surface energy and fewer interfaces at which rutile can nucleate. Thus, the transition to rutile and grain growth of anatase can be considered as competing phenomena [205].

Significant rutile grain growth is exhibited as the anatase to rutile transition proceeds $[67,73,108,158,170,176,177$, 208]. Rutile grains coarsen at the expense of neighbouring anatase during coalescence until the large rutile grains begin to impinge on each other $[111,114]$. This increase in grain size causes a decrease in surface area and a consequent decrease in photocatalytic activity $[55,73,131]$.

Grain boundary effects

Dopant oxides that do not dissolve and remain on the grain boundaries restrict the grain growth and reduce 
interparticle contact, thereby impeding the phase transformation $[87,170]$.

Also, the presence of a liquid or vitreous phase on the grain boundaries generally represents a hindrance to diffusion and so it is expected that titania contaminated with silica or another glass former would be likely to inhibit the phase transformation [209].

\section{Summary}

An understanding of the transformation of anatase to rutile is of great importance to those studying $\mathrm{TiO}_{2}$ for photocatalysis or other applications. The phase composition of the material has significant consequences on its properties and performance and therefore it may be desirable to enhance or inhibit the transformation to give a particular phase or phase mixture subsequent to thermal treatment.

At all temperatures and pressures, rutile is the stable phase of $\mathrm{TiO}_{2}$. Anatase is metastable but it can be considered to be kinetically stabilised at lower temperatures. Although rutile is the more stable phase from a thermodynamic point of view, anatase frequently is the product phase in the synthesis of $\mathrm{TiO}_{2}$ owing to its less constrained structure and consequent enhanced kinetics of formation. The phase transformation of kinetically stabilised anatase to thermodynamically stable rutile does not have a distinct transformation temperature. Rather, it shows a gradual onset, the temperature of which is highly dependent on numerous parameters pertaining to the nature of the material, the thermal treatment, and measurement method. The transformation rate to rutile increases exponentially as the temperature increases.

The transformation of anatase to rutile can be promoted, accelerating its kinetics and causing it to become observable at lower temperatures and to progress more quickly. Alternatively, the transformation can be inhibited, retarding the kinetics and causing it to become observable only at higher temperatures. The latter also can be referred to as the stabilisation of anatase even though it is the less stable phase.

The kinetics of the anatase to rutile transformation are affected strongly by oxygen defect levels, where oxygen vacancies enhance the transformation. The oxygen defect levels are influenced by atmospheric conditions, reduction or oxidation reactions, unintentional impurities, and intentional dopants.

Dopants are an effective method for influencing the kinetics of the anatase to rutile transformation. Various cationic dopants have been shown to have a strong influence on the phase transformation through the change in oxygen vacancies. This effect can be seen clearly in Fig. 11, which separates inhibitors and promoters in terms of the combined effects of their ionic radii and valence. Substitutional cationic dopants can increase (promoters) or decrease (inhibitors) oxygen vacancy levels through valence effects, alteration in cation coordination, or reduction/oxidation effects. However, the presence of interstitial ions (lattice constraint) and the reduction of interparticle contact (grain boundary phases) in anatase act to inhibit the transformation. Most doping ultimately increases the thermal stability of anatase. The effects of anionic dopants have been reported to a lesser degree.

The consideration of the mechanisms by which the anatase to rutile transformation is inhibited or promoted can enable prediction of the effects that various dopants and experimental conditions are likely to have on the chemistry, mineralogy, and phase assemblage of the resultant titania, as shown in Figs. 12 and 13. This ultimately can assist in facilitating the optimisation of the activity of titanium dioxide photocatalysts.

\section{References}

1. Ding XZ, Liu XH, He YZ (1996) J Mater Sci Lett $15: 1789$

2. Jamieson J, Olinger B (1969) Miner Notes 54:1477

3. Gamboa JA, Pasquevich DM (1992) J Am Ceram Soc 75:2934

4. Pistorius C (1976) Prog Solid State Chem II:1

5. Smith SJ, Stevens R, Liu S, Li G, Navrotsky A, Boerio-Goates J, Woodfield BF (2009) Am Miner 94:236

6. Ghosh TB, Dhabal S, Datta AK (2003) J Appl Phys 94:4577

7. Murrray JL, Wriedy HA (1987) Bull Alloy Phase Diagr 8:148

8. Beltran A, Gracia L, Andres J (2006) J Phys Chem B 110:23417

9. Muscat J, Swamy V, Harrison NM (2002) Phys Rev B 65:224112

10. Arlt T, Bermejo M, Blanco M, Gerward L (2000) Phys Rev B 61:14414

11. Ren R, Yang Z, Shaw LL (2000) J Mater Sci 35:6015. doi: 10.1023/A:1026751017284

12. Dubrovinskaia NA, Dubrovinsky LS, Ahuja R, Prokopenko VB, Dmitriev V, Weber HP, Osorio-Guillen JM, Johansson B (2001) Phys Rev Lett 87:275501

13. Fisher J, Egerton TA (2001) Titanium compounds, inorganic, Kirk-Othmer encyclopaedia of chemical technology. Wiley, New York

14. Peters G, Vill V (1989) Index of modern inorganic compounds. Subvolume A. Landolt-Börnstein numerical data and functional relationships in science and technology. Verlag, Berlin

15. Burdett JK, Hughbanks T, Miller GJ, Richardson JW Jr, Smith JV (1987) J Am Chem Soc 109:3639

16. Hahn T (1988) International tables for crystallography. Reidel, Dordrecht

17. Madhusudan Reddy K, Manorama SV, Ramachandra Reddy A (2003) Mater Chem Phys 78:239

18. Serpone N (2006) J Phys Chem B 110:24287

19. Daude N, Gout C, Jouanin C (1977) Phys Rev B 15:3229

20. Wang H, Lewis JP (2006) J Phys Condensed Matter 18:421

21. Mardare D, Tasca M, Delibas M, Rusu GI (2000) Appl Surf Sci 156:200

22. CERAM (2002) Titanium dioxide-titania, AZoM version 2.0, AZoM Pty. Ltd 
23. Ohno T, Sarukawa K, Matsumura M (2001) J Phys Chem B 105:2417

24. Anatase and Rutile Mineral Data

25. Sun J, Gao L, Zhang Q (2003) J Am Ceram Soc 86:1677

26. Fujihara K, Ohno T, Matsumura M (1998) J Chem Soc Faraday Trans 94:3705

27. Fujishima A, Honda K (1972) Nature 238:37

28. Linsebigler A, Lu G, Yates JT (1995) Chem Rev 95:735

29. Ni M, Leung M, Leung D, Sumathy K (2007) Renew Sustain Energy Rev 11:401

30. Wold A (1993) Chem Mater 5:280

31. Gratzel M (2005) Inorg Chem 44:6841

32. Huang SY, Schlichthorl G, Nozik AJ, Gratzel M, Frank AJ (1997) J Phys Chem B 101:2576

33. O'Regan B, Gratzel M (1991) Nature 335:737

34. Muggli DS, DIng L (2001) Appl Catal B 32:184

35. Fujishima A, Zhang X, Tryk DA (2008) Surf Sci Rep 63:515

36. Bessekhouad Y, Robert D, Weber JV (2003) Int J Photoenergy 5:153

37. Pozzo RL, Baltanas MA, Cassano AE (1997) Catal Today $39: 219$

38. Matthews RW (1987) J Phys Chem 91:3328

39. Okamoto K, Yamamoto Y, Tanaka H, Tanaka M (1985) Bull Chem Soc Jpn 58:2015

40. Baram N, Starosvetsky D, Starosvetsky J, Epshtein M, Armon R, Ein-Eli Y (2007) Electrochem Commun 9:1684

41. Carneiro JO, Teixeira V, Portinha A, Magalhaes A, Countinho P, Tavares CJ (2007) Mater Sci Eng B 138:144

42. Carp O, Huisman CL, Reller A (2004) Prog Solid State Chem 21:33

43. Franch M, Peral J, Domenech X, Ayllon JA (2005) Chem Commun 14:1851

44. Haick H, Paz Y (2001) J Phys Chem B 105:3045

45. Lee SK, McIntyre S, Mills A (2004) J Photochem Photobiol A $162: 203$

46. Mills A, Elliot N, Hill G, Fallis D, Durrant J, Willis R (2003) Photochem Photobiol Sci 2:591

47. Mills A, Hodgen S, Lee SK (2004) Res Chem Intermed 31:295

48. Mills A, Wang J, Crow M (2006) Chemosphere 64:1032

49. Paz Y, Heller A (1997) J Mater Res 12:2759

50. Sam ED, Urgen M, Tepehan FZ, Gunay V (2004) Key Eng Mater 264:407

51. Mills A, Lepre A, Elliott N, Bhopal S, Parkin IP, O’Neill SA (2003) J Photochem Photobiol A 160:213

52. Mitoraj D, Janczyk A, Strus M, Kisch H, Stochel G, Heczko PB, Macyk W (2007) Photochem Photobiol Sci 6:642

53. Kisch H, Burgeth G, Macyk W (2004) Adv Inorg Chem $56: 241$

54. Bacsa RR, Kiwi J (1998) Appl Catal B 16:19

55. Zhang Q, Gao L, Guo J (2000) Appl Catal B 26:207

56. Ranjit KT, Cohen H, Willner I, Bossmann S, Braun AM (1999) J Mater Sci 34:5273. doi:10.1023/A:1004780401030

57. Herrmann JM (1999) Catal Today 53:115

58. Sclafani A, Herrmann JM (1996) J Phys Chem 100:13655

59. Gaya UI, Abdullah AH (2008) J Photochem Photobiol C 9:1

60. Fox MA, Dulay MT (1992) Chem Rev 93:341

61. Fujishima A, Rao TN, Tryk DA (2000) J Photochem Photobiol C $1: 1$

62. Mott NF, Allgaier RS (1967) Phys Status Solidi (b) 21:343

63. Barzykin AV, Tachiya M (2002) J Phys Chem B 106:4356

64. Yu JC, Yu J, Ho W, Jiang Z, Zhang L (2002) Chem Mater $14: 3808$

65. Hoffmann MR, Martin ST, Choi W, Bahnemann DW (1995) Chem Rev 95:69

66. Hirano M, Nakahara N, Ota K, Tanaike O, Inagaki N (2003) J Solid State Chem 170:39
67. Riyas S, Krishnan G, Mohandas PN (2007) Adv Appl Ceram 106:255

68. Sun B, Vorontsov AV, Smirniotis PG (2003) Langmuir 19:3151 69. Hadjiivanov K, Klissurski DG (1996) Chem Soc Rev 25:61

70. Setiawati E, Kawano K (2008) J Alloys Compd 451:293

71. Augustynski J (1993) Electrochim Acta 38:43

72. Sumita T, Yamaki T, Yamamoto S, Miyashita A (2002) Appl Surf Sci 200:21

73. Zhang Z, Wang C, Zakaria R, Ying J (1998) J Phys Chem B 102:10871

74. Kesselman JM, Shreve GA, Hoffmann MR, Lewis NS (1994) J Phys Chem 98:13385

75. Lewis NS, Rosenbluth ML (1989) In: Serpone N, Pellizzetti E (eds) Photocatalysis. Wiley, New York, p 99

76. Zhang H, Banfield JF (1998) J Mater Chem 8:2073

77. Rupp F, Scheideler L, Olshanska N, De Wild M, Wieland M, Geis-Gerstorfer J (2006) J Biomed Mater Res A 76:323

78. Ohno T, Tokieda K, Higashida S, Matsumura M (2003) Appl Catal A 244:383

79. Kavan L, Gratzel M, Gilbert SE, Klemenz C, Scheel HJ (1996) J Am Chem Soc 118:6716

80. Bickley RI, Gonzalez-Carreno T, Lees JS, Palmisano L, Tilley RJD (1991) J Solid State Chem 92:178

81. Ohno T, Haga D, Fujihara K, Kaizaki K, Matsumura M (1997) J Phys Chem B 101:6415

82. Okada K, Yamamoto N, Kameshima Y, Yasumori A (2001) J Am Ceram Soc 84:1591

83. Shin H, Jung HS, Hong KS, Lee JK (2005) J Solid State Chem $178: 15$

84. Matthews A (1976) Am Miner 61:419

85. Fang CS, Chen YW (2003) Mater Chem Phys 78:739

86. Park HK, Kim DK, Kim CH (1997) J Am Ceram Soc 80:743

87. Yang J, Fereira JMF (1998) Mater Res Bull 33:389

88. Sharma SD, Singh D, Saini K, Kant C, Sharma V, Jain SC, Sharma CP (2006) Appl Catal A 314:40

89. Smirnova N, Eremenko A, Vladimir G, Irina P, Yuriy G, Galina K, Andrey K, Alexej C (2004) J Sol-Gel Sci Technol 32:357

90. Takahashi Y, Matsuoka Y (1988) J Mater Sci 23:2259. doi: 10.1007/BF01115798

91. Volz HG (2006) Pigments, inorganic Ullman's encyclopedia of industrial chemistry. Wiley-VCH Verlag $\mathrm{GmbH} \& \mathrm{Co}$, Weinheim

92. Teleki A, Pratsinis SE, Kalyanasundaram K, Gouma PI (2006) Sens Actuators B 119:683

93. Skandan G, Chen YJ, Glumac N, Kear BH (1999) Nanostruct Mater 11:149

94. Wu M, Lin G, Chen D, Wang G, He D, Feng S, Xu R (2002) Chem Mater 14:1974

95. Wang CC, Ying JY (1999) Chem Mater 11:3113

96. Cheng H, Ma J, Zhao Z, Qi L (1995) Chem Mater 7:663

97. Oguri Y, Riman RE, Bowen HK (1988) J Mater Sci 23:2897. doi:10.1007/BF00547465

98. Ovenstone J, Yanagisawa K (1999) Chem Mater 11:2770

99. Li G, Li L, Boerio-Goates J, Woodfield BF (2005) J Am Chem Soc $127: 8659$

100. Mills A, Elliott N, Parkin IP, O'Neill SA, Clark RJ (2002) J Photochem Photobiol A 151:171

101. Goossens A, Maloney EL, Schoonman J (1998) Chem Vapor Depos 4:109

102. Meyer S, Gorges R, Kreisel G (2004) Thin Solid Films 450:276

103. Li G, Li L, Boerio-Goates J, Woodfield BF (2003) J Mater Res $18: 2664$

104. Li G, Boerio-Goates J, Woodfield BF, Li L (2004) Appl Phys Lett 85:2059

105. Kumar KNP, Keizer K, Burggraaf AJ (1994) J Mater Sci Lett $13: 59$ 
106. Penn RL, Banfield JF (1999) Am Miner 84:871

107. Rothschild A, Levakov A, Shapira Y, Ashkenasy N, Komem Y (2003) Surf Sci 532:456

108. Kim J, Song KC, Foncillas S, Pratsinis S (2001) J Eur Ceram Soc 21:2863

109. Shannon RD, Pask JA (1965) J Am Ceram Soc 48:391

110. Zhang H, Banfield JF (2000) J Mater Res 15:437

111. Gouma PI, Mills MJ (2001) J Am Ceram Soc 84:619

112. Jing Z, Qian X, Zhaochi F, Meijun L, Can L (2008) Angew Chem Int Ed 47:1766

113. Rao CNR (1961) Can J Chem 39:498

114. Hyoung GL, Zuo JM (2004) J Am Ceram Soc 87:473

115. Cox PA (1992) Transition metal oxides: an introduction to their electronic structure and properties. Clarendon Press, Oxford

116. Harold KH (1989) Transition metal oxides: surface chemistry and catalysis. Elsevier, Oxford

117. Batzill M, Morales EH, Diebold U (2006) Phys Rev Lett 96:26103

118. Craido J, Real C (1983) J Chem Soc Faraday Trans 79:2765

119. Rao C, Turner AG, Honeg JM (1959) Phys Chem Solids 11:173

120. Akhtar MK, Pratsinis SE, Mastrangelo SVR (1992) J Am Ceram Soc 75:3408

121. Hu Y, Tsai HL, Huang CL (2003) Mater Sci Eng A 344:209

122. Yin S, Yamaki H, Komatsu M, Zhang Q, Wang J, Tang Q, Saito F, Sato T (2003) J Mater Chem 13:2996

123. Kumar KNP (1995) Scripta Metall Mater 32:873

124. Arbiol J, Cerda J, Dezanneau G, Cirera A, Peiro F, Cornet A, Morante JR (2002) J Appl Phys 92:853

125. Loddo V, Marci G, Palmisano L, Sclafani A (1998) Mater Chem Phys 53:217

126. Spurr RA, Myers H (1957) Anal Chem 29:760

127. Iida Y, Ozaki S (1961) J Am Ceram Soc 44:120

128. Zhang YH, Reller A (2002) Mater Sci Eng C 19:323

129. Hanaor D (2007) Thesis. The School of Materials Science and Engineering, UNSW

130. Ocana M, Garcia-Ramos JV, Serna CJ (1992) J Am Ceram Soc 75:2010

131. Suzana M, Francisco P, Mastelaro VR (2002) Chem Mater $14: 2514$

132. Busca G, Ramis G, Gallardo J, Escribano VS, Piaggio P (1994) J Chem Soc Faraday Trans 90:3181

133. Chang H, Huang PJ (1998) J Raman Spectrosc 29:97

134. Clegg IM, Everall NJ, King B, Melvin H, Norton C (2001) Appl Spectrose 55:1138

135. Howard CJ, Sabine TM, Dickson F (1991) Acta Crystallogr B 47:462

136. Renishaw minerals \& inorganic materials database (2010) Renishaw plc In

137. ICDD, Powder Diffraction File, Newtown Square, Pennsylvania, USA

138. Ohno T, Sarukawa K, Tokieda K, Matsumura M (2001) J Catal 203:82

139. Suresh C, Biju V, Warrier K (1998) Polyhedron 17:3131

140. Rajesh Kumar S, Suresh C, Vasudevan AK, Suja NR, Mukundan P, Warrier KGK (1999) Mater Lett 38:161

141. Colombo D, Phillip JR, Bowman RM (1996) J Phys Chem 100: 18445

142. Hurum DC, Gray KA, Rajh T, Thurnauer M (2005) J Phys Chem B 109:977

143. Goto H, Hanada Y, Ohno T, Matsumura M (2004) J Catal 225:223

144. Hurum DC, Agrios AG, Crist SE, Gray KA, Rajh T, Thurnauer MC (2006) J Electron Spectrosc Relat Phenom 150:155

145. Li G, Chen L, Graham ME, Gray KA (2007) J Mol Catal A 275:30

146. Sun B, Smirniotis PG (2003) Catal Today $88: 49$
147. Hurum DC, Agrios AG, Gray KA, Rajh T, Thurnauer MC (2003) J Phys Chem B 107:4545

148. Navrotsky A, Kleppa OJ (1967) J Am Ceram Soc 50:626

149. Shi ZM, Yan L, Jin LN, Lu XM, Zhao G (2007) J Non-Cryst Solids 353:2171

150. Hu L, Yoko T, Kozuka H, Sakka S (1992) Thin Solid Films 219:18

151. Nagaveni K, Hegde MS, Ravishankar N, Subbanna GN, Madrass G (2004) Langmuir 20:2900

152. Mitsuhashi T, Kleppa OJ (1979) J Am Ceram Soc 62:356

153. Stull DR, Prophet H (1971) NBS STP NO 37, Washington DC, $1141 \mathrm{p}$

154. Dachille F, Simons PY, Roy R (1968) Am Miner 53:1929

155. Yang J, Huang YX, Ferreira JMF (1997) J Mater Sci Lett 16:1933

156. Gribb AA, Banfield JF (1997) Am Miner 82:717

157. Vargas S, Arroyo R, Haro E, Rodriguez R (1999) J Mater Res $14: 3932$

158. Kumar KNP, Fray DJ, Nair J, Mizukami F, Okubu T (2007) Scripta Mater 57:771

159. Liao SC, Chen YJ, Mayo WE, Kear BH (1999) Nanostruct Mater 11:553

160. Liao SC, Colaizzi J, Chen Y, Kear BH, Mayo WE (2000) J Am Ceram Soc 83:2163

161. Meng D, Wu X, Fan X, Zhang Z, Chen H, Meng X, Zheng J (2008) Acta Geol Sin (English Edition) 82:371

162. Ihara $\mathrm{T}$, Miyoshi M, Iriyama $\mathrm{Y}$, Matsumoto $\mathrm{O}$, Sugihara $\mathrm{S}$ (2003) Appl Catal B 42:403

163. Nowotny J, Bak T, Sheppard LR, Sorrell CC (2007) Adv Solar Energy Annu Rev Res Dev 17:169

164. Mackenzie KJD (1975) Trans J Br Ceram Soc 74:77

165. MacKenzie KJD (1975) Trans J Br Ceram Soc 74:29

166. Syarif DG, Miyashita A, Yamaki T, Sumita T, Choi Y, Itoh H (2002) Appl Surf Sci 193:287

167. Heald EF, Weiss CW (1972) Am Miner 57:10

168. Sundman B (1991) J Phase Equilib 12:127

169. Wang ZL, Yin JS, Mo WD, Zhangs ZJ (1997) J Phys Chem B 101:6793

170. Reidy DJ, Holmes JD, Morris MA (2006) J Eur Ceram Soc 26:1527

171. Janes R, Knightley LJ, Harding CJ (2004) Dyes Pigments 62:199

172. Yang Y, Li X, Chen J, Wang L (2004) J Photochem Photobiol A 163:517

173. Shannon RD (1976) Acta Crystallogr A 32:751

174. Chen CH, Kelder EM, Schoonman J (1999) Thin Solid Films 342:35

175. Yang J, Ferreira JMF (1998) Mater Lett 36:320

176. Kumar SR, Pillai SC, Hareesh US, Mukundan P, Warrier KGK (2000) Mater Lett 43:286

177. Perera S, Gillan EG (2005) Chem Commun 48:5988

178. Debeila MA, Raphulu MC, Mokoena E, Avalos M, Petranovskii V, Coville NJ, Scurrell MS (2005) Mater Sci Eng A 396:61

179. Francisco MSP, Mastelaro VR (2002) Chem Mater 14:2514

180. Zhang Y, Xu H, Xu Y, Zhang H, Wang Y (2005) J Photochem Photobiol A 170:279

181. Hishita S, Mutoh I (1983) Ceram Int 9:61

182. Baiju KV, Sibu CP, Rajesh K, Pillai PK, Mukundan P, Warrier KGK, Wunderlich W (2005) Mater Chem Phys 90:123

183. Heo KC, Ok CI, Kim JW, Moon BK (2005) J Korean Phys Soc 47:861

184. Arroyo R, Cordoba G, Padilla J, Lara VH (2002) Mater Lett 54:397

185. Karvinen S (2003) Solid State Sci 5:811

186. Jaroenworaluck A, Sunsan W, Stevens R (2007) Key Eng Mater 334-335:1101 
187. Li C, Shi L, Xie D, Du H (2006) J Non-Cryst Solids 352:4128

188. Venezia AM, Palmisano L, Schiavello M (1995) J Solid State Chem 114:364

189. Nair J, Nair P, Mizukami F, Oosawa Y, Okubo T (1999) Mater Res Bull 34:1275

190. Eppler RA (1987) J Am Ceram Soc 70:64

191. Bond GC, Sarkany AJ, Parfitt GD (1979) J Catal 57:476

192. Gennari FC, Pasquevich DM (1998) J Mater Sci 33:1571. doi: 1023/A:1017515804370

193. Hume-Rothery W, Smallman RE, Haworth CW (1988) The institute of metals, 1 Carlton House Terrace, London SW 1 Y 5 DB, UK, 1988

194. Borkar SA, Dharwadkar SR (2004) J Therm Anal Calorim 78:761

195. Li J (1992) Mater Res 7:3349

196. Reidy DJ, Holmes JD, Morris MA (2006) Ceram Int 32:235

197. Aruna ST, Tirosh S, Zaban A (2000) J Mater Chem 10:2388

198. Bak T, Nowotny J, Rekas M, Sorrell CC (2003) J Phys Chem Solids 64:1043
199. Bak T, Nowotny J, Rekas M, Sorrell CC (2003) J Phys Chem Solids 64:1069

200. Bak T, Nowotny J, Rekas M, Sorrell CC (2003) J Phys Chem Solids 64:1057

201. Gopal M, Moberly Chan WJ, De Jonghe LC (1997) J Mater Sci 32:6001. doi:10.1023/A:1018671212890

202. Li Y, Liu J, Jia Z (2005) Mater Lett 60:1753

203. Yin S, Hasegawa H, Maeda D, Ishitsuka M, Sato T (2004) J Photochem Photobiol A 163:1

204. Tang Z, Zhang J, Cheng Z, Zhang Z (2003) Mater Chem Phys $77: 314$

205. Ding X, Li X (1998) J Mater Res 13:2556

206. Gilbert B, Zhang H, Huang F, Finnegan M, Wayachunas GA, Banfield JF (2003) Geochem Trans 4:20

207. Zhang H, Banfield JF (2000) J Phys Chem B 104:3481

208. Park JK, Ahn J-P, Kim G (1999) Metals Mater 5:129

209. Kingery WD, Bowen HK, Uhlmann DR (1976) Introduction to ceramics. Wiley-Interscience, New York, p 460 